\title{
Trastorno de estrés postraumático en adultos
}

\author{
Intervención cognitivo-conductual \\ para víctimas de sismos
}

Leonardo Reynoso Erazo

Ana Leticia Becerra Gálvez

Isaías Vicente Lugo González

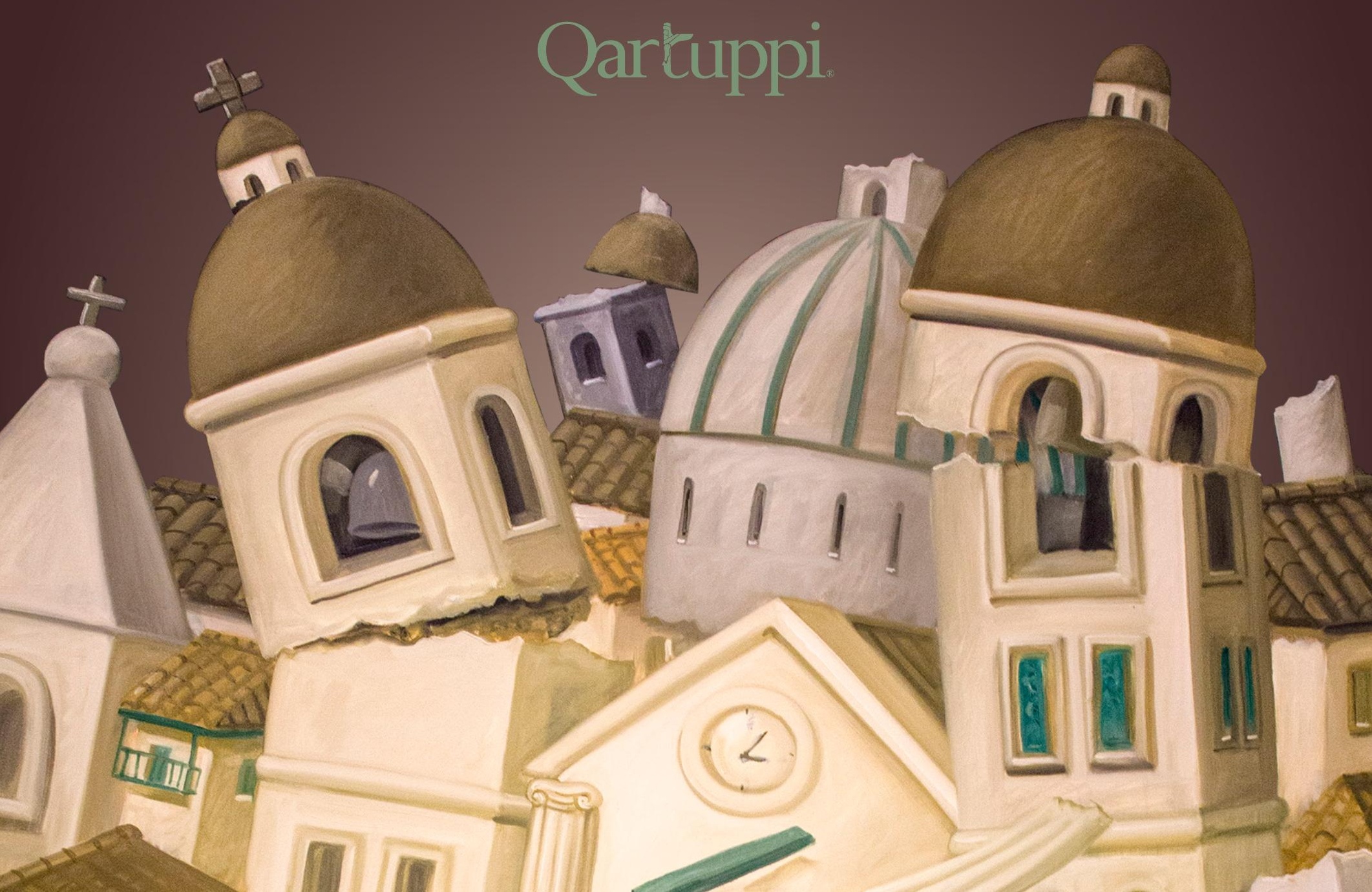




\section{(c) $\underset{\mathrm{BY}}{(\mathrm{i})(\mathrm{NC})}$}

Esta obra se publica bajo una Licencia Creative Commons Atribución-NoComercial 4.0 Internacional.

https://creativecommons.org/licenses/by-nc/4.0/deed.es 


\title{
Trastorno de estrés \\ postraumático en adultos
}

Intervención cognitivo-conductual para víctimas de sismos

\author{
Leonardo Reynoso Erazo \\ Ana Leticia Becerra Gálvez \\ Isaías Vicente Lugo González
}

Qartuppi. 
Obra revisada por:

Everardo Camacho Guitiérrez

Benjamín Domínguez Trejo

Rosa Martha Meda Lara

Trastorno de estrés postraumático en adultos

Intervención cognitivo-conductual para víctimas de sismos

1era edición, febrero 2019

ISBN 978-607-98270-7-6

DOI 10.29410/QTP.19.02

D.R. @ C 2019. Qartuppi, S. de R.L. de C.V.

Villa Turca 17, Villas del Mediterráneo

Hermosillo, Son. 83220 México

http://www.qartuppi.com

Diseño y Edición: Qartuppi, S. de R.L. de C.V.

Portada: Detalle de "Terremoto en Popayán" (1999) de Fernando Botero

Derechos: ( Museo Botero - Banco de la República (Colombia)

Fotografía: León Felipe Irigoyen Morales 


\section{Índice}

7 Prólogo

11 Introducción

15 Capítulo 1

Estrés: trastorno de estrés agudo (TEA) y trastorno de estrés postraumático (TEPT)

35 Capítulo 2

Evaluación conductual del TEPT

47 Capítulo 3

Técnicas de intervención cognitivo-conductual para el TEPT

69 Capítulo 4

Características del terapeuta que atiende al paciente con TEPT

75 Referencias

85 Anexos

91 Acerca de los autores y revisores 


\section{Prólogo}

Este documento surge como respuesta a los sismos ocurridos en México en septiembre del 2017, que provocaron estragos en el territorio nacional y no sólo representaron pérdidas materiales sino también pérdidas humanas, incertidumbre, miedo y desamparo en aquellos adultos y niños que presenciaron dichos desastres naturales.

Los sismos, en su carácter más estricto, son acontecimientos imposibles de predecir y, por lo tanto, difíciles de controlar; lo anterior, provoca miedo para aquellos que han vivido un fenómeno parecido (como el sismo ocurrido el 19 de septiembre de 1985) y también en aquellos que lo viven por primera vez. Desafortunadamente, los intentos gubernamentales y locales por crear una cultura del sismo son insuficientes, pues se carece de información, infraestructura y programas encaminados a salvaguardar a la población.

Después de un sismo es de esperarse que el sentido de alerta, el miedo y el malestar emocional se hagan presentes, generando afectaciones en la calidad de vida de las personas aun cuando el evento traumático haya ocurrido. Es entonces que la atención psicológica oportuna se hace fundamental y debe centrarse en la adquisición de conductas que coloquen a los sobrevivientes en un proceso de adaptación y de acción al repetirse un fenómeno similar.

Durante estos desastres, la población civil desempeñó un papel activo para la movilización de apoyo económico, instrumental y, quizás el más importante, el recurso humano. Fue sorprendente ver grupos de voluntarios en los diferentes centros de acopio 
y las denominadas zonas "cero" proporcionando ayuda, haciendo cadenas humanas, levantando escombros y prestando atención médica y psicológica. Interesante fue observar que la población joven de nuestro país levantó la mano para ofrecer su apoyo, olvidándose del cansancio y fijándose la meta de ayudar al otro sin la expectativa de recibir algo a cambio. Profesionales de la salud como médicos, enfermeras y psicólogos titulados o en formación prestaron sus servicios en el entendido de que lo mejor que podían hacer en ese momento era ayudar a aquellos a los que el sismo les había arrebatado la tranquilidad.

Las buenas intenciones, el valor de la empatía y el altruismo fueron cualidades que presentaron algunos psicólogos que aún sin conocer la dimensión del problema y los protocolos de intervención, proporcionaban "a tientas" y desde su sentido común ese "apoyo psicológico", ya que en ese momento prevalecía el impulso de ayudar. Lo cierto es que, a pesar de las buenas intenciones, los lugares donde se presentaban las crisis se encontraban abarrotados de psicólogos que, más que ayudar, entorpecían los esfuerzos por rescatar vidas. Se olvidaron (¿o ignoraban?) que lo más difícil vendría después.

De ninguna manera se pretende desacreditar los intentos de apoyo y los esfuerzos realizados, sin embargo, nos es imprescindible hacer notar que no todos contaban con las habilidades para proporcionar en el carácter estrictamente profesional y ético aquello que se necesitaba, por ello, se crearon diferentes alternativas educativas que ofertaban cursos de entrenamiento para la atención de la crisis y primeros auxilios psicológicos, dejando claro una vez más que no estamos listos para atender este tipo de problemas y no todos pueden -ni deben- ofrecer el apoyo.

Actualmente, se siguen registrando muchos problemas, a saber: apoyos económicos que no llegaron a su destino, personas que no han recibido el recurso suficiente para la reconstrucción de sus casas y, por supuesto, las secuelas que a nivel psicológico dejó el sismo. Lo real es que, pese a estas buenas acciones, se perdió de vista lo que pasaría después, trastornos adaptativos, ansiedad, depresión y el denominado trastorno de estrés postraumático, tema central de este documento.

Esperamos que esta propuesta permita dar a conocer a psicólogos titulados y en formación algunas bases conceptuales y metodológicas para la intervención con adultos que sufren este trastorno, de tal suerte que se realicen las adaptaciones necesarias en cada uno de ellos. 
No pretendemos decir que las recomendaciones que se describen en este documento deben ser puestas en práctica tal cual se indica en ella o que es la propuesta, por el contrario, queremos hacer ver a los lectores que no se pueden perder de vista las particularidades del individuo durante la atención clínica, y se deben conocer las diferentes formas en las que pueden interactuar el comportamiento, las cogniciones y las emociones ante un mismo acontecimiento.

Esto no es una receta o una guía en donde sólo se necesita ejecutar, por el contrario, son directrices y procedimientos que cuentan con suficiente evidencia empírica de su eficacia en este tipo de trastornos, pero que son susceptibles de cambio. 


\section{Introducción}

Para sobrevivir, el ser humano debe ser capaz de distinguir entre situaciones agradables y de riesgo. Una vez que el individuo valora dichas situaciones se generan respuestas específicas que dependen, en gran medida, de la interpretación que se haga de los eventos. Para ilustrar este fenómeno, imagine por unos instantes el miedo que está experimentado al detectar una señal ambiental de alarma, como, por ejemplo, un sismo. Ante un evento de esta naturaleza se inicia una cadena de reacciones reflejas, que se acompaña de emociones, pensamientos y otras acciones, que pueden estar presentes por minutos, horas o días. De esta forma, se desencadena el estrés, proceso que depende de la evaluación del contexto en el que se presentan los estímulos, de la historia de respuesta de la persona y de la evaluación que se realice de la situación como amenazante, neutral o benigna (Lazarus \& Folkman, 1984; Lazarus, 1999; Meichenbaum, 1987; Meichenbaum, 2017; Reynoso-Erazo \& Seligson, 2005; Snyder, 2001).

Cuando hay estrés también hay emociones; estas aparecen como consecuencia de la valoración que se realiza del evento en el que nos encontremos inmersos, cuando los consideramos como amenazantes, desafiantes o dañinos. Las emociones y el estrés utilizan dos vías de expresión: la primera, de forma casi inmediata, consiste en la activación del sistema nervioso simpático, por lo que, ante eventos estresantes que generan emociones, éstas van aparejadas con datos fisiológicos como aumento del diámetro de las pupilas, resequedad de la boca, el corazón se acelera y podemos notarlo por la sen- 
sación de palpitaciones o, bien, al tomarnos el pulso y encontrar la frecuencia cardiaca elevada. La presión arterial también aumenta, así como la frecuencia respiratoria y puede aparecer sudoración en algunas partes del cuerpo, sensación de frío, además de la liberación de catecolaminas (adrenalina y noradrenalina) a la circulación, con lo que los efectos fisiológicos mencionados permanecen durante más tiempo. La segunda, la activación del sistema endócrino, la cual se inicia en el eje hipotálamo-hipófisis-suprarrenales. Por señal del hipotálamo, la hipófisis secreta corticotropina (también conocida como ACTH, por sus siglas en inglés), hormona que provoca que la corteza suprarrenal produzca glucocorticoides (el más abundante y conocido es el cortisol) y mineralocorticoides (la más abundante es la aldosterona). Dichas hormonas, al ser liberadas a la circulación provocan aumento de los niveles de glucosa, además de retención de sodio y agua, para mantener el estrés dándole un fondo metabólico estable (Barrett, Boitano, Barman \& Brooks, 2010).

Gracias al estrés agudo intentamos hacer frente a las exigencias ambientales y buscamos resolver la situación o escapar de ésta, además de disminuir la actividad autonómica, lo que nos permite autorregularnos. Cuando una persona vivió un evento sumamente estresante como un sismo y estuvo en lugares de desastre, perdió algún ser querido, estuvo atrapado entre escombros, participó en labores de rescate o de atención a las víctimas de dicho evento, se esperaría que, en un período no muy largo, por lo general algunos días, el estrés se redujera y los recuerdos fuesen menores, debido en buena medida a las actividades cotidianas. Pero, en ocasiones, el evento estresante se hace presente en forma de recuerdos, los cuales pueden ser extremadamente vívidos, capaces de generar emociones y mantener la activación fisiológica, provocando entonces que la persona tenga alteraciones para iniciar el sueño o presentar pesadillas recurrentes del evento, que le interrumpen el descanso (Bridges \& Jones, 1967).

Durante el día, puede presentar conductas evitativas (como no acercarse a personas o lugares relacionadas con el evento traumático o evitar hablar del tema), todo ello puede acompañarse de alteraciones del estado de ánimo, por lo que su comportamiento variaría, desde la pérdida de interés por cosas y eventos hasta el comportamiento ansioso, pudiendo entonces oscilar desde una supuesta calma hasta episodios de furia sin control aparente y sin un disparador presente a excepción de los recuerdos (memoria) (De la Rosa \& Cárdenas, 2012; Foa \& Kozak, 1986). Estas condiciones impiden el buen funcionamiento de la persona, de allí la importancia de identificar de manera temprana 
el problema a través de la elaboración de un cuidadoso análisis del problema para iniciar su tratamiento y evitar, en la medida de lo posible, la aparición de recaídas y enfermedades posteriores (Dedert, Calhoun, Watkins, Sherwood \& Beckham, 2010; Meadows \& Foa, 1999; Prakash, Saha, Das, Srivastava \& Shashikuma, 2016).

Preocupados por el creciente número de personas que pueden padecer estos problemas, que genéricamente se conocen como trastorno de estrés postraumático, ofrecemos esta propuesta. Nuestro objetivo es brindar a los profesionales de la psicología una serie de lineamientos, pasos y estrategias a considerar en la evaluación e intervención con enfoque cognitivo-conductual de adultos con trastorno de estrés postraumático, el cual será referido con las siglas TEPT. 


\section{Capítulo 1}

\section{Estrés: Trastorno de estrés agudo (TEA) \\ y Trastorno de estrés postraumático (TEPT)}

\section{Conceptualización de estrés}

La descripción conceptual del estrés se remonta a los estudios experimentales realizados por Cannon (1932), los cuales permitieron describir la coexistencia de una serie de reacciones fisiológicas ante condiciones estimulares amenazantes; dichas reacciones le permitían al sujeto experimental huir o defenderse.

Posteriormente, Selye (1936 como se citó en Selye, 1998) retomó los conceptos de Cannon y los agrupó en un conjunto de signos y síntomas denominados Síndrome General de Adaptación y posteriormente estrés, el cual se presenta ante una variedad de estímulos, se inicia de manera refleja e incluye cambios fisiológicos temporales (aumento en el diámetro pupilar, resequedad de la mucosa oral, aumento del diámetro bronquial, elevación de la frecuencia cardiaca y de la presión arterial, piloerección, aumento del flujo sanguíneo a músculos, pulmones y corazón, disminución de la motilidad intestinal, relajación de la musculatura de la vejiga urinaria y contracción del esfínter vesical, además de la secreción de catecolaminas al torrente sanguíneo provenientes de la médula suprarrenal) producto de la activación del organismo. Las reacciones fisiológicas de un organismo ante estimulación estresante son bien conocidas (Bridges \& Jones, 1967; Jones, Bridges \& Leak, 1970) y pueden ser elicitadas con relativa facilidad ante estímulos poderosos, tanto en animales experimentales como en los seres humanos en condiciones de la vida real, como, por ejemplo, el estar involucrado en desastres naturales. 
En la actualidad existen diferentes modelos teóricos que pretenden explicar el funcionamiento del estrés. Sin embargo, el modelo que ha resultado de particular importancia es el desarrollado por Lazarus y Folkman en 1984. Para estos autores, el estrés se origina con una evaluación inicial en que la situación demanda una respuesta efectiva para evitar o reducir el daño físico o psicológico, en ese sentido, el sujeto entonces intenta responder, responde equivocadamente o no responde. La respuesta (o su ausencia) tiene repercusiones ambientales y altera la situación. Entonces, se pueden producir una serie de acontecimientos, evaluaciones, respuestas y transformaciones situacionales. Estas secuencias dejan de ser estresantes cuando el sujeto evalúa que el reto ha pasado, ya sea espontáneamente o porque una adecuada respuesta de afrontamiento ha neutralizado la amenaza (Lazarus \& Folkman, 1984). Así, existe un interjuego entre el individuo y la situación que determina el inicio, magnitud, duración y calidad del episodio estresante.

El estrés está determinado por un amplio número de factores personales y situacionales e incluye una serie de evaluaciones por parte del sujeto como (Lazarus \&Folkman, 1984):

1. Evaluación primaria. Básicamente consiste en un proceso mediador que permite distinguir las situaciones potencialmente amenazantes de las benéficas o de las que no tienen importancia.

2. Evaluación secundaria. El paciente examina los recursos de los cuales dispone para enfrentar la situación percibida como amenazante.

3. Reevaluación. Se modifica la percepción original de la situación debido a las condiciones cambiantes del ambiente o a los cambios internos que se suscitan en él.

Lazarus y Folkman (1984) describen algunos factores que hacen que las situaciones que experimentan las personas resulten en estrés (Tabla 1.1.).

El modelo transaccional, aunque fue propuesto hace muchos años, sigue vigente y a la fecha se considera entre los más adecuados para describir el proceso de estrés, por lo tanto, es de utilidad para explicar el funcionamiento del trastorno de estrés agudo (TEA) y el trastorno de estrés postraumático (TEPT).

A continuación, se realizará una descripción de las características del TEA y del TEPT, esto con el fin de que el lector identifique las diferencias clínicas que permitan el adecuado diagnóstico de este tipo de trastornos. 
Tabla 1.1. Factores situacionales que favorecen la presencia de estrés

\begin{tabular}{ll} 
Novedad & $\begin{array}{l}\text { Situaciones completamente nuevas y sin experiencia previa (al } \\
\text { ser novedosa es, en sí misma, percibida como amenazante). }\end{array}$ \\
\hline Predictibilidad & $\begin{array}{l}\text { Obedece a las características ambientales predecibles que pue- } \\
\text { den ser discernidas, descubiertas o aprendidas. }\end{array}$ \\
\hline Eventos inciertos & $\begin{array}{l}\text { Estos eventos introducen la noción de probabilidad y, en cir- } \\
\text { cunstancias naturales, al tener la peculiaridad de ser inciertos se } \\
\text { genera incertidumbre y son altamente estresantes. }\end{array}$ \\
\hline Factores temporales & $\begin{array}{l}\text { Hacen referencia a la inminencia, duración e incertidumbre } \\
\text { temporal. }\end{array}$ \\
\hline Ambigüedad & $\begin{array}{l}\text { Cuando la información que necesitamos para hacer la valora- } \\
\text { ción del acontecimiento no es suficiente o clara, el entorno pa- } \\
\text { rece ambiguo. }\end{array}$ \\
\hline $\begin{array}{l}\text { Programación de eventos } \\
\text { estresantes en relación con } \\
\text { el ciclo de vida }\end{array}$ & $\begin{array}{l}\text { Un acontecimiento estresante no ocurre en el vacío sino en el } \\
\text { contexto de ciclo de vida y en relación con otros acontecimien- } \\
\text { tos distantes, recientes o concurrentes. }\end{array}$
\end{tabular}

\section{Trastorno de estrés agudo}

Un episodio de estrés agudo se caracteriza por desencadenarse prácticamente de forma automática; imagine el lector que se encuentra al momento de cruzar una calle, inicia la caminata y súbitamente tras de sí escucha el rechinar de llantas sobre el pavimento. Al voltear puede advertir un vehículo que se encuentra muy cercano a usted; en ese instante se sucedieron una serie de eventos: se desencadenaron reflejos y se produjeron cambios, todo ello con el fin de proveer al organismo de ajustes fisiológicos que le permitieran huir.

Simultáneamente a los cambios señalados, se realiza una evaluación de la situación que le permite decidir si un evento de este tipo ya le ha sucedido, si considera que el evento es amenazante y si hay historia de cómo se enfrentó a dicho evento, para responder-además de con un movimiento que lo aleje del problema- con otras respuestas para reducir o eliminar la amenaza.

El ejemplo anterior permite señalar que necesitamos distinguir entre situaciones favorables y situaciones peligrosas; para ello, debemos señalar que esa distinción implica valorar o evaluar y, a partir de dicha evaluación, decidir si contamos con las estrategias 
para hacerle frente a la situación. Si consideramos que la situación es difícil de controlar o que no se cuenta con los recursos para hacerle frente a la misma, entonces se puede decir que la persona se encuentra en estrés agudo, y gracias a esto, se producirán emociones. En el caso de los sismos, las respuestas de estrés comienzan al escuchar la señal de alarma sísmica, provocando evaluaciones y respuestas encadenadas que incluyen comportamientos manifiestos y encubiertos.

Entonces, cuando se evalúa una situación como estresante, la persona se pregunta de manera automática: ¿Cuál es la naturaleza de la amenaza? ¿Qué tan inminente es? ¿Me puede dañar? Posteriormente, se revisan las condiciones propias de la persona (su biología, su historia y sus alternativas de comportamiento) para poder responder: ¿He estado en una situación similar previamente? Y, si la respuesta es afirmativa: ¿Cómo controlé la situación previamente? ¿Funcionó? Por otra parte, y con relación a la biología de la persona: ¿Mis capacidades (en términos de fisiología) se encuentran intactas? ¿Qué tan deteriorado físicamente me encuentro? ¿Seré capaz de enfrentar la amenaza? Si nuestra evaluación nos ofrece evidencia de que no contamos con los recursos para hacer frente a dichas demandas, entonces estaremos en la condición de estrés agudo. Al presentar este tipo de respuesta simultáneamente se expresarán emociones (miedo, enojo, desamparo, etc.), las cuales se acompañan de cambios fisiológicos, principalmente en los sistemas cardiovascular y nervioso. Todas estas respuestas en su conjunto mantienen al ser humano en un proceso de hipervigilancia, por lo que, si esta condición persiste en el tiempo, es posible que pueda afectar nuestra salud, de allí la importancia de buscar alternativas para reducirlas.

A pesar de que el modelo transaccional del estrés de Lazarus y Folkman se caracteriza por tener una estructura interactiva entre la percepción del individuo, sus recursos de afrontamiento y las condiciones del contexto que generan a su vez la respuesta de estrés, la forma en la que se manifiesta el estrés agudo obedece, en efecto, a estos elementos, como se observa en la Figura 1.1. 


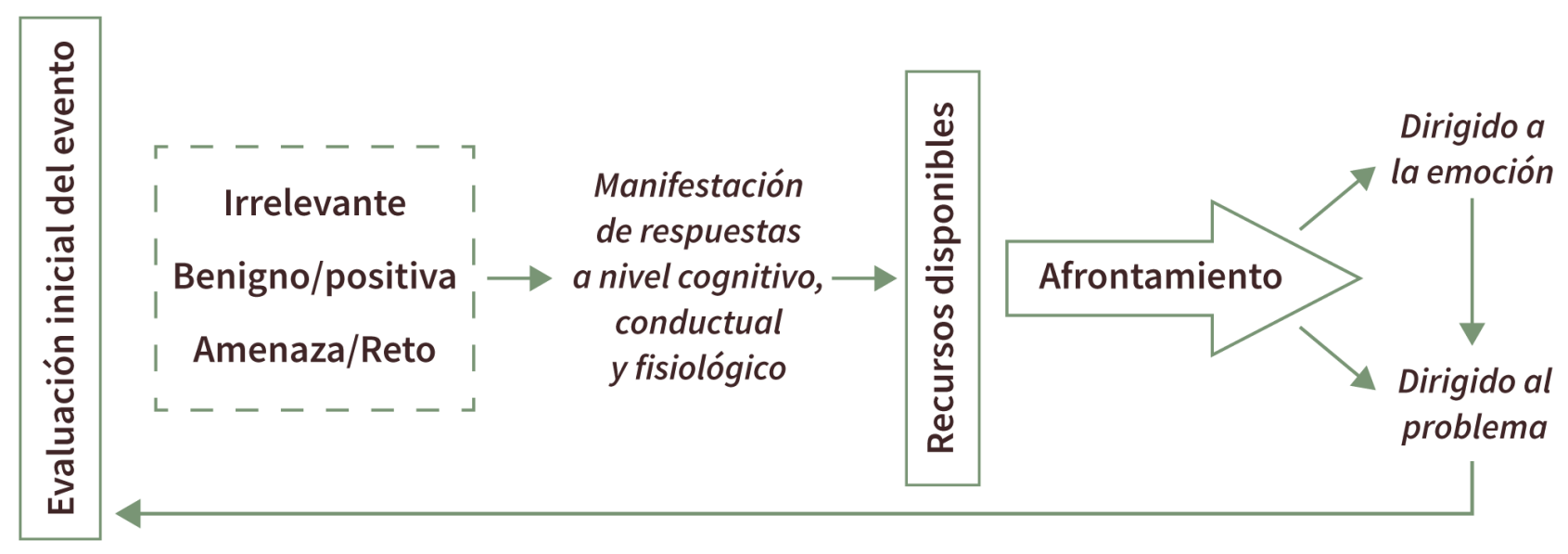

Figura 1.1. Funcionamiento del TEA.

Para reduciry, finalmente, detener el estrés debemos realizar acciones para combatir y transformar la situación, para manejar la emoción o para alejarnos del problema. Este tipo de acciones se denominan genéricamente afrontamiento (Lazarus \& Folkman, 1984). El afrontamiento, entonces, se refiere a los esfuerzos necesarios para manejar las demandas estresantes, independientemente del resultado. El mejor afrontamiento es aquel que modifica la relación individuo-entorno en el sentido de mejorarla y puede considerarse como equivalente a la solución efectiva de un problema (Reynoso \& Seligson, 2005).

Durante una interacción estresante, el individuo evalúa lo que está ocurriendo y lo que puede hacer al respecto y se utilizan estrategias de afrontamiento que se pueden dirigir hacia el problema o bien, hacia la emoción que causa el problema no resuelto. El afrontamiento incluye mucho más que la resolución de un problema y que su desarrollo efectivo sirva también a otras funciones. La función del afrontamiento tiene que ver con el objetivo que persigue cada estrategia: resolver el problema, atender las respuestas emocionales o ambas.

\section{Criterios diagnósticos del TEA}

Según la American Psychiatric Association (APA, 2013), en el Manual Diagnóstico y Estadístico de los Trastornos Mentales (DSM-5, por sus siglas en inglés), el trastorno de estrés agudo (TEA) se caracteriza por la presencia de respuestas cognitivas, emocionales y conductuales en un período de tres días a un mes después de la exposición a uno o más eventos traumáticos. En la Tabla 1.2. se observan los criterios diagnósticos según este manual. 


\section{Tabla 1.2. Criterios diagnósticos para el TEA}

a. Exposición a la muerte, lesión grave o violencia sexual ya sea real o amenaza, en una (o más) de las siguientes formas:

- Experiencia directa del suceso(s) traumático(s).

- Presencia directa del suceso(s) ocurrido(s) a otros.

- Conocimiento de que el suceso(s) traumático(s) ha ocurrido a un familiar próximo o a un amigo íntimo.

- Exposición repetida o extrema a detalles repulsivos del suceso(s) traumático(s).

b. Presencia de nueve (o más) de los síntomas siguientes de alguna de las cinco categorías.

- Síntomas de intrusión: recuerdos o sueños angustiosos recurrentes, reacciones disociativas (por ejemplo, escenas retrospectivas como si se repitiera el suceso traumático), pérdida de la orientación en el entorno presente, reacciones fisiológicas importantes en respuesta a factores internos o externos que simbolizan o se parecen a un aspecto del suceso traumático.

- Estado de ánimo negativo: incapacidad de experimentar emociones positivas.

- Síntomas disociativos: sentido de realidad alterado del entorno o de uno mismo, incapacidad para recordar aspectos importantes del suceso traumático.

- Síntomas de evitación: esfuerzos por evitar recuerdos, pensamientos o sentimientos angustiosos asociados al suceso(s) traumático(s), evitar el contacto con recordatorios externos (lugares, conversaciones, personas, situaciones) que despierten recuerdos o sentimientos angustiosos relacionados al suceso(s) traumático(s).

- Síntomas de alerta: alteración del sueño, comportamiento irritable o arrebatos de furia que se traducen en agresión verbal o física contra personas u objetos, hipervigilancia, problemas con la concentración y respuesta de sobresalto exagerada.

C. La duración del trastorno (síntomas del criterio B) es de tres días a un mes después de la exposición al trauma.

d. La alteración causa malestar clínicamente significativo o deterioro en lo social, laboral, u otras áreas del funcionamiento.

e. La alteración no se puede atribuir a los efectos fisiológicos de una sustancia u otra afección médica y no se explica mejor por un trastorno psicótico breve. 


\section{Trastorno de estrés postraumático}

El trastorno de estrés postraumático (TEPT) es un problema de salud que se presenta con frecuencia posterior a eventos traumáticos (como en el caso de los terremotos); la relevancia de éste estriba en su sintomatología, debido a las molestias que ocasiona, además de que altera el funcionamiento global de quien lo padece y que se puede tornar crónico y debilitante (Saaren, 2014).

Desde 1980, la American Psychiatric Association aceptó formalmente al trastorno de estrés postraumático como una categoría psiquiátrica en el Diagnostic and Statistical Manual of Mental Disorders versión III (DSM-III). Esto, posterior a los acontecimientos y consecuencias psicológicas presentadas en los veteranos y sobrevivientes tras la Segunda Guerra Mundial (Echterling, Field \& Stewart, 2015). Dicho trastorno ha sido modificado en cada una de las versiones del DSM hasta llegar a los criterios que se conocen en la última versión de este documento, en donde no sólo pueden identificarse los criterios diagnósticos para los adultos sino también para los menores de edad. A pesar de estas modificaciones, la columna vertebral de este trastorno sigue siendo la exposición física a un estímulo estresante presente en el ambiente.

Aunque la definición de TEPT ha variado entre las distintas ediciones del DSM, existen cuatro características que han permanecido estables para el diagnóstico:

1. Haber experimentado o haber sido testigo de un evento estresante.

2. Reexperimentar los síntomas del evento que incluyen pesadillas y/o flashbacks.

3. Esforzarse por evitar situaciones, lugares y personas que le recuerden el evento traumático.

4. Síntomas como irritabilidad, problemas de concentración y trastornos del sueño (Saaren, 2014) (Figura 1.2.). 


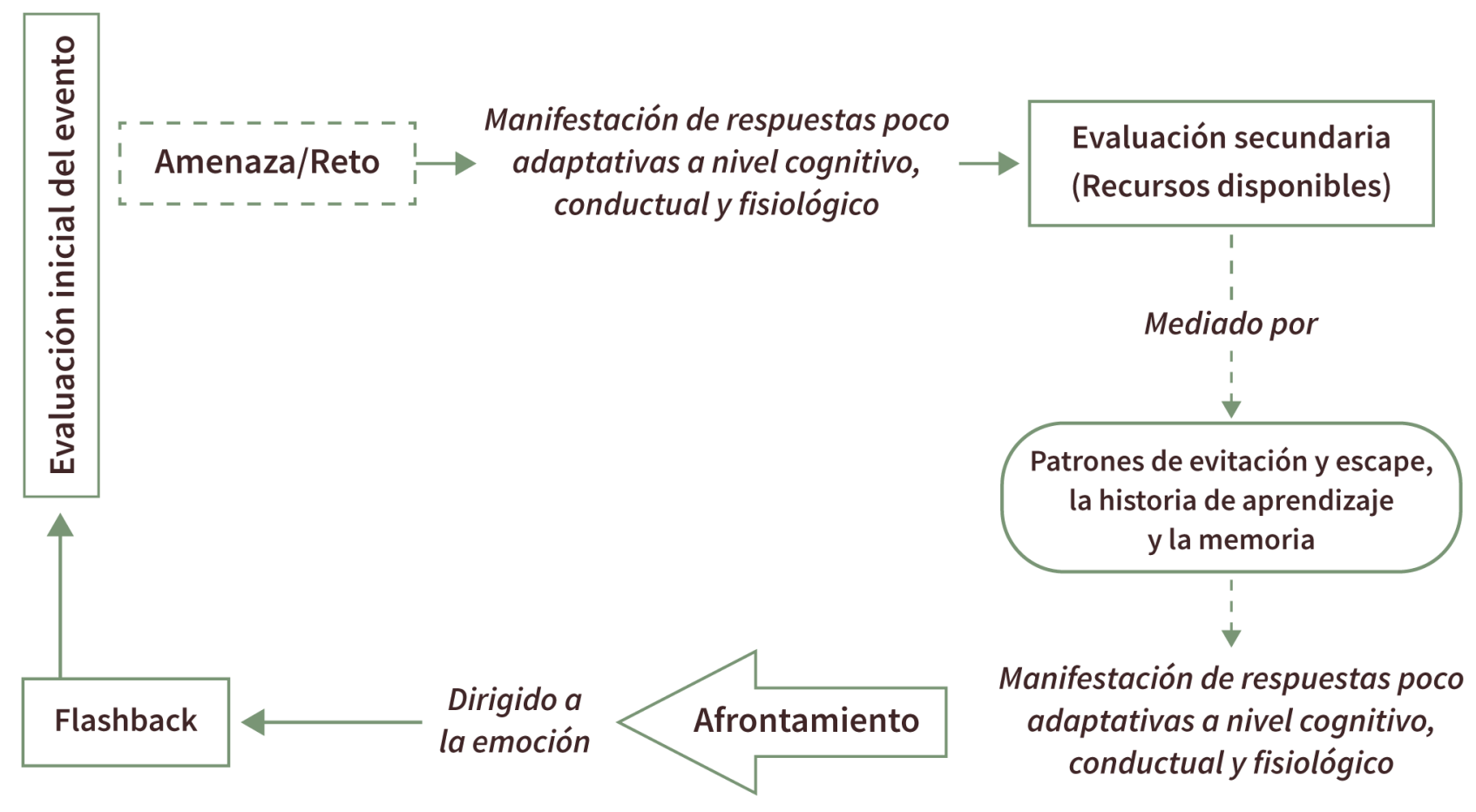

Figura 1.2. Funcionamiento del TEPT.

\section{Modelos teóricos del TEPT}

Para Vargas y Coria (2017), algunos modelos teóricos que han servido de explicación para el TETP son:

- Teoría del Procesamiento Emocional propuesta en 1986 por Foa y Kozak. Esta teoría supone la existencia de estructuras internas que almacenan información importante para resguardar la vida, que se derivan de experiencias y las cuales ante estímulos similares provocan respuestas parecidas a las almacenadas en esta red o estructura, por tanto, la resolución de la re-experimentación del trauma sólo ocurre mediante la integración y organización de la información en la memoria.

- Teoría de la Representación Dual propuesta en 2001 por Brewin. Esta teoría considera la existencia de dos sistemas de representación en la memoria, las cuales funcionan en paralelo, durante y después del trauma (memoria verbal accesible y memoria situacional accesible). La memoria verbal accesible posee la información procesada de manera consciente durante y después del trauma, mientras que la memoria situacional accesible contiene información más amplia, pero con menor procesamiento perceptual de la escena traumática. 
- Modelo de SPAARS propuesto por Power y Dalgleish en 2006. Este modelo, derivado de una teoría cognitiva, menciona que existen cuatro niveles de representación; los sistemas esquemáticos, los proposicionales, los analógicos y los asociativos representacionales. El TEPT entonces se presenta cuando la información relacionada al trauma es incompatible con los modelos esquemáticos que tienen los individuos de sí mismos, el mundo y las demás personas, por tanto, toda aquella información que se integre adecuadamente a cada uno de los niveles resultará en evitación e hiperactivación.

- Modelo Bifactorial de Mowrer propuesto en 1960. Para este modelo, el TEPT puede explicarse por medio de la asociación entre estímulos y las consecuencias secundarias que le siguen, es decir, los estímulos que se presentan en un evento traumático adquieren una carga aversiva que antes no tenían (acontecimientos y estímulos visuales, auditivos y sonoros característicos o relacionados al trauma). Cuando estos estímulos se presentan a la par, estímulos neutrales pueden llegar a producir las mismas respuestas en los individuos por simple condicionamiento respondiente y una vez relacionados adquieren en consecuencia propiedades aversivas; en este sentido, si el individuo tiene ante la presencia del estímulo aversivo comportamientos de evitación y escape y, además, con ello obtiene ganancias secundarias (como por ejemplo atención de otros), entonces lo evitará y dicha conducta será mantenida por sus consecuencias, funcionando así de manera operante. $\mathrm{El}$ TEPT entonces se establece cuando este patrón conductual de evitación genera a largo plazo consecuencias negativas en la vida de las personas.

- Modelo Conductual Contextual del Estrés Postraumático. Este modelo parte de las premisas del Modelo Bifactorial de Mowrer, pero considera las condiciones contextuales y funcionales para explicar dicho trastorno. Parte del supuesto de que la evitación experiencial mantiene y agrava los síntomas del TEPT, mientras que la fusión cognitiva (las respuestas del individuo que son guiadas por los acontecimientos verbales y no por eventos ambientales) propicia que los patrones de comportamiento desadaptativo se hagan persistentes y generalizados. 


\section{Factores de riesgo y factores de protección asociados al TEPT}

Según el DSM-5, no existen datos precisos en relación a la prevalencia del TEPT, sin embargo, la probabilidad de que se presente está condicionada por las diferencias culturales y el riesgo de exposición traumática (en personas con riesgo de exposición elevado como, por ejemplo, policías, bomberos y personal médico de urgencias). El TEPT puede presentarse en adultos y niños. Los síntomas inician dentro de los primeros tres meses, aunque puede también tomar un mayor tiempo, a este fenómeno se le denomina "expresión retrasada", la presencia de los síntomas suele variar en intensidad y frecuencia a lo largo del tiempo, por lo que será responsabilidad del psicólogo observar cada uno de los cambios que presenta el paciente en el curso del trastorno. En la Tabla 1.3. se pueden observar los factores de riesgo asociados con el TEPT, así como su clasificación (Loo et al., 2016; McBride et al., 2018).

\section{Tabla 1.3. Factores de riesgo asociados al TEPT}

\section{Factores pretraumáticos}

- Antecedentes psicológicos de relevancia. Antecedentes de problemas emocionales en la infancia (a partir de los 6 años) y antecedentes de trastornos de ansiedad y depresión

- Ambientales. Bajo nivel socio-económico-educativo, estrategias de afrontamiento evitativas y centradas en la emoción

- Genéticos y fisiológicos. Prevalece más en pacientes del sexo femenino jóvenes en el momento de la exposición al trauma

\section{Factores peritraumáticos}

- Ambientales. Gravedad del estímulo traumático (a mayor magnitud mayor probabilidad de presentar el trastorno), lesiones personales, ser autor o testigo de alguna atrocidad

\section{Factores postraumáticos}

- Historia de afrontamiento. Estrategias de enfrentamiento inadecuadas y el desarrollo de un trastorno de estrés agudo

- Ambientales. Exposición a recuerdos, acontecimientos adversos posteriores y déficit en redes de apoyo funcionales 
Si bien, es cierto que la reacción psicológica derivada de un evento traumático que culmina en la presentación de un TEPT depende, entre otras variables, de la intensidad del trauma, de las circunstancias del suceso y de los factores pretraumáticos, peritraumáticos y postraumáticos, existen algunos factores que reducen la vulnerabilidad para presentar este trastorno y funcionan como protectores para el adecuado afrontamiento del suceso traumático (McBride et al., 2018; San Juan, 2001). Algunos de los elementos que interactúan y configuran un sistema de protección para presentar en el TEPT se muestran en la Tabla 1.4.

\section{Tabla 1.4. Factores de protección asociados al TEPT}

\section{Factores de protección de carácter psicológico}

- Resistencia al estrés.

- Estilos y estrategias de afrontamiento funcionales y adaptativas previas al evento traumático.

\section{Factores de protección de carácter informativo}

- Información válida y confiable de carácter público relacionada al control de los efectos derivados del evento traumático o las directrices de atención a seguir con las víctimas de un evento traumático.

\section{Factores de protección de carácter social/institucional}

- Asistencia institucional oportuna para el control de la prevalencia de factores que favorecen el TEPT (asistencia médica, social, legal y sanitaria).

\section{Factores de protección de carácter familiar/interpersonal}

- Poseer una adecuada red de apoyo social próxima (familia, amigos, miembros de la comunidad) antes de la exposición al suceso traumático.

- Recibir apoyo social (emocional, informativo, financiero, etc.) posterior al evento.

Ahora que ya se conocen las características generales del TEPT y los factores de riesgo y de protección, en el siguiente apartado se describirán los criterios diagnósticos para este trastorno. 


\section{Criterios Diagnósticos del TEPT}

En la Tabla 1.5. se muestran los criterios nosológicos para el adecuado diagnóstico de TEPT determinados por el DSM-5 (APA, 2013).

\section{Tabla 1.5. Criterios diagnósticos para el TEPT}

a. Exposición a la muerte, lesión grave o violencia sexual, ya sea real o amenaza, en una (o más) de las formas siguientes:

- Experiencia directa del suceso traumático

- Presencia directa del suceso ocurrido a otros

- Conocimiento de que el suceso ha ocurrido a un familiar próximo o a un amigo. En los casos de amenaza o realidad de muerte de un familiar o amigo, el suceso ha de haber sido violento $o$ accidental

- Exposición repetida o extrema a detalles repulsivos de sucesos traumáticos (por ejemplo, socorristas que recogen restos humanos)

El criterio 4 no se aplica a la exposición a través de medios electrónicos, a menos que esta exposición esté relacionada con el trabajo.

b. Presencia de uno (o más) de los síntomas de intrusión siguientes asociados al suceso traumático, que comienza después del suceso traumático:

- Recuerdos angustiosos recurrentes, involuntarios e intrusivos del suceso traumático (en niños mayores de 6 años, juegos repetitivos en los que se expresen aspectos del suceso traumático)

- Sueños angustiosos recurrentes en los que el contenido esté relacionado con el suceso traumático (en niños, sueños aterradores sin contenido reconocible)

- Reacciones disociativas en las que el sujeto siente o actúa como si se repitiera el suceso traumático

- Malestar psicológico intenso o prolongado al exponerse a factores que simbolizan o se parecen a un aspecto del suceso traumático

- Reacciones fisiológicas intensas a factores internos o externos que simbolizan o se parecen a un aspecto del suceso traumático

c. Evitación persistente de estímulos asociados al suceso traumático, que comienza tras el suceso txraumático:

- Evitación o esfuerzos para evitar recuerdos, pensamientos o sentimientos angustiosos relacionados con el suceso 
- Evitación o esfuerzos para evitar recordatorios externos (personas, lugares, conversaciones, actividades, objetos, situaciones) que despiertan recuerdos, pensamientos o sentimientos angustiosos acerca del suceso

d. Alteraciones cognitivas y del estado de ánimo asociadas al suceso traumático, que comienzan y empeoran después del suceso:

- Incapacidad de recordar un aspecto importante del suceso, debido típicamente a amnesia disociativa y no a lesión cerebral, alcohol o drogas

- Creencias o expectativas negativas persistentes y exageradas sobre uno mismo, los demás o el mundo

- Percepción distorsionada persistente de la causa o las consecuencias del suceso, que hace que el individuo se acuse a sí mismo o a los demás

- Estado emocional negativo persistente (miedo, terror, enfado, culpa o vergüenza)

- Disminución del interés o la participación en actividades significativas

- Sentimiento de desapego o extrañamiento de los demás

- Incapacidad persistente de experimentar emociones positivas (felicidad, satisfacción, sentimientos amorosos)

e. Alteración de la alerta y reactividad asociada al suceso traumático, que comienza o empeora después del suceso:

- Comportamiento irritable y arrebatos de furia (con poca o ninguna provocación) que se expresan típicamente como agresión verbal o física contra personas u objetos

- Comportamiento imprudente o autodestructivo

- Hipervigilancia

- Respuesta de sobresalto exagerada

- Problemas de concentración

- Alteración del sueño (dificultad para conciliar o continuar el sueño o sueño inquieto)

f. La duración de la alteración (criterios B, C, D y E) es superior a un mes.

g. La alteración causa malestar clínicamente significativo o deterioro en lo social, laboral u otras áreas importantes del funcionamiento.

h. La alteración no se puede atribuir a los efectos fisiológicos de una sustancia (medicamentos, alcohol) o a otra afección médica.

El TEPT se asocia en un $80 \%$ de los casos con otro tipo de trastornos, por ejemplo, trastornos depresivos, trastornos de ansiedad y trastornos asociados con el consumo de sustancias (Dedert et al., 2010; APA, 2013; Foa \& Kozak, 1986). 


\section{Prevalencia del TEPT en México}

En México no se dispone de estadística en relación con el TEPT; sin embargo, la Encuesta Nacional de Epidemiología Psiquiátrica reporta que el 1.4\% de la población fue diagnosticado con este trastorno, siendo el sexo femenino el que cuenta con una mayor prevalencia con un $2.3 \%$. Las causas más comunes asociadas con la aparición de este problema se relacionan con actos de violencia física, secuestros, violaciones y accidentes (Medina-Mora et al., 2005).

Al respecto, la Secretaría de Salud en la Guía de Práctica Clínica para el Diagnóstico y Manejo del Estrés Postraumático (SSA, 2011) señala que este tipo de trastornos representa un problema de salud pues está constituido por un deterioro funcional y discapacidad en aquellos que lo padecen, además sólo el 13.9\% solicita apoyo médico para su tratamiento (6.6\% asiste con el médico general no especialista en psiquiatría y el $7.3 \%$ con algún especialista relacionado con la salud mental).

A pesar de que los datos que se disponen en México asocian, principalmente, al TEPT con actos de violencia, no se puede descartar su vínculo con la experimentación de fenómenos naturales, como los terremotos. En el apartado siguiente se abordará con mayor detalle este tema.

\section{Trastorno de estrés postraumático y desastres naturales}

Según la Organización Panamericana de la Salud (OPS, 2000), el término desastre se refiere a los fenómenos naturales, pero también a la susceptibilidad de una población o un sistema a los efectos del peligro (por ejemplo, deficiencia en el acceso a la salud, abastecimiento de agua potable, riesgos sanitarios, deficiencias en el sistema de drenaje). Ante este tipo de fenómenos, los dos elementos de importancia son la asistencia humanitaria en salud y el uso de los recursos para la restauración material.

Una catástrofe natural se conceptualiza como un acontecimiento grave y de gran magnitud que desborda los recursos no sólo de la población civil sino también los recursos gubernamentales (OPS, 2006). Requiere en esa medida, la puesta en marcha de respuestas inmediatas, coordinadas y efectivas que permitan el mayor ajuste y recuperación posible ante las consecuencias que se derivan del mismo (Galindo, 2010; San Juan, 2001). Entre los desastres naturales más comunes se encuentran los sismos o terremotos que, por su carácter incierto y las consecuencias derivadas, pueden ser potenciales eventos 
traumáticos y, por tanto, funcionar como el inicio de un TEA o un TEPT. Si bien, es cierto que en los sismos no existe información o directrices que nos permitan identificar el tiempo en que se presentará, dado que funcionan como un estímulo aversivo de intervalo variable, se puede entrenar al paciente que ha sido víctima no sólo en el control de las respuestas sino también en una serie de habilidades de afrontamiento que permitan actuar de forma funcional ante eventos similares. La atención psicológica oportuna durante un evento de tal magnitud se vuelve fundamental, ya que este tipo de fenómenos naturales suelen afectar considerablemente la conformación social y el estado psicológico de los individuos como se observa en la Tabla 1.6.

\section{Tabla 1.6. Desastre natural y sus implicaciones sociales y psicológicas}

\section{Implicaciones sociales}

- Ruptura de la estructura social que no puede ser modificada por los mecanismos sociales habituales (requiere tiempo, apoyo económico y humanitario nacional e internacional)

- Las víctimas no siempre poseen la habilidad para ajustarse a la crisis y de racionar la cantidad de ayuda disponible (en un inicio el apoyo suele ser suficiente e incluso sobrepasar las expectativas, pero con el paso del tiempo es insuficiente)

- La concepción social del desastre varía con el tiempo y en función de las creencias de las diferentes comunidades

- El aumento de la frecuencia en los desastres naturales provoca una elevación del umbral y, por tanto, una disminución en la capacidad de recuperación y ajuste

\section{Implicaciones psicológicas}

- Sentimientos de intenso molestar, desamparo e indefensión

- Miedo a perder la vida y la de otros miembros de la familia

- Sentimientos encontrados entre ansiedad y empatía

- Temor, frustración o culpabilidad generados como señal y reacción de alarma ante el evento estresor o traumático

- Sensación de impotencia y pérdida de la sensación de autocontrol y autoeficacia

- Pérdida de memoria, concentración y atención respecto de asuntos vitales o solución de problemas

- Presencia de comportamientos desadaptativos y poco organizados en términos de funcionalidad y recuperación de rutinas habituales 
A ese respecto, es importante mencionar que México es uno de los territorios con mayor actividad sísmica, tan sólo en 2017 e inicios de 2018 se registraron una serie de sismos mayores a los 6 grados en la escala Richter, provocando estragos considerables a nivel material y emocional. Según el Servicio Sismológico Nacional de la Universidad Nacional Autónoma de México (UNAM, 2017), de enero a noviembre del 2017 se han registrado un total de 22,126 sismos con una magnitud que oscila entre los 0.5 y los 7.5 grados. Los sismos registrados como más fuertes ocurrieron el mes de septiembre de 2017 como se observa en la Tabla 1.7.

Tabla 1.7. Desastre natural y sus implicaciones sociales y psicológicas

\begin{tabular}{|c|c|c|c|c|c|c|}
\hline Fecha & Hora & Latitud & Longitud & Profundidad & Magnitud & Localización \\
\hline $14 / 06 / 17$ & 02:29:03 & 14.77 & -92.08 & 113 km & 7.0 & $\begin{array}{l}13 \mathrm{~km} \text { al noroeste de } \\
\text { Cd. Hidalgo, Chiapas }\end{array}$ \\
\hline $7 / 09 / 17$ & $23: 49: 18$ & 14.85 & -94.11 & $58 \mathrm{~km}$ & 8.2 & $\begin{array}{l}133 \text { km al suroeste de } \\
\text { Pijijiapan, Chiapas }\end{array}$ \\
\hline $8 / 09 / 17$ & $00: 17: 42$ & 15.62 & -94.85 & $32 \mathrm{~km}$ & 6.1 & $\begin{array}{l}72 \text { km al suroeste de } \\
\text { Salina Cruz, Oaxaca }\end{array}$ \\
\hline $19 / 09 / 17$ & $13: 14: 40$ & 18.4 & -98.72 & $57 \mathrm{~km}$ & 7.1 & $\begin{array}{l}12 \mathrm{~km} \text { al suroeste de } \\
\text { Axochiapan, Morelos }\end{array}$ \\
\hline $23 / 09 / 17$ & 07:52:59 & 16.48 & -94.9 & $75 \mathrm{~km}$ & 6.1 & $\begin{array}{l}7 \text { km al oeste de Unión } \\
\text { Hidalgo, Oaxaca }\end{array}$ \\
\hline $19 / 01 / 18$ & $10: 17: 45$ & 26.66 & -111.1 & $16 \mathrm{~km}$ & 6.3 & $\begin{array}{l}76 \mathrm{~km} \text { al noroeste de } \\
\text { Loreto, BCS }\end{array}$ \\
\hline $16 / 02 / 18$ & $17: 39: 38$ & 16.25 & -98.03 & $12 \mathrm{~km}$ & 7.2 & $\begin{array}{l}11 \text { km al sur de } \\
\text { Pinotepa Nacional, } \\
\text { Oaxaca }\end{array}$ \\
\hline $19 / 02 / 18$ & $00: 56: 59$ & 16.25 & -97.77 & $10 \mathrm{~km}$ & 6.0 & $\begin{array}{l}32 \text { km al suroeste de } \\
\text { Pinotepa Nacional, } \\
\text { Oaxaca }\end{array}$ \\
\hline
\end{tabular}

Fuente: Elaboración propia con base en "Sismos Fuertes" por UNAM, 2017, Servicio Sismológico Nacional. 
Aunque los sismos se encuentran entre los desastres naturales más comunes, se ha prestado escasa atención a las consecuencias psicológicas en las personas que lo viven. El TEPT se encuentra como un factor común entre aquellos que han padecido un terremoto, con incidencia de entre 2 a 87\% de los casos (Goenjian et al., 1994, 2000; McBride et al., 2018; McMillen, North \& Smith, 2000; Sharan, Chaudhary, Kavathekar \& Saxena, 1996).

Tapia, Sepúlveda, Medina, Caraveo y De la Fuente (1987) realizaron un estudio con personas sobrevivientes de los sismos de la Ciudad de México en 1985, las cuales se encontraban resguardadas en albergues locales, con la finalidad de identificar aquellos casos en donde se presentó TEPT. Los resultados reportaron que 32\% de la población estudiada presentaba síntomas de estrés postraumático como angustia generalizada, agitación, temblor, dificultad para concentrarse, trastornos del sueño (insomnio y pesadillas) y alteraciones psicofisiológicas asociadas. Estos síntomas se presentaron hasta un año después del terremoto.

En esta misma línea, los estudios realizados por Başoglu, Kiliç, Şalcioglu y Livanou, (2004) y Chan et al. (2011) reportan que las víctimas de TEPT post terremoto presentan los siguientes factores de riesgo para la aparición del trastorno:

1. Edad. A mayor edad en los pacientes se incrementa el riesgo de presentar el trastorno.

2. Educación. Niveles bajos de escolaridad se asocian con un incremento en el riesgo y mayor prevalencia de las respuestas emocionales asociadas al TEPT.

3. Grado de exposición al terremoto. Si el paciente posee una mayor cercanía con el sismo (en términos de la vivencia o las pérdidas materiales y humanas) sufre de mayores problemas de adaptación y prevalencia del malestar emocional.

4. Permanecer atrapado en los escombros durante el sismo.

5. Muerte de seres queridos. La pérdida de un integrante de la familia representa una ruptura en esta unidad que socioculturalmente proporciona sustento a la sociedad.

6. Pérdida de bienes materiales (inmuebles y muebles).

7. Participación en las acciones de rescate y movilización de escombros.

8. Redes de apoyo deficientes y disfuncionales. 
Existe consenso entre los estudiosos de eventos traumáticos, pues se cree que aquellas personas expuestas a este tipo de sucesos experimentan problemas como depresión, ansiedad y TEPT (Flett, Kanzantzis, Long, MacDonald \& Millar, 2002; Friedman \&Schnurr, 1995; Galea, Nandi \& Vlahov, 2005; Kessler, Sonnega, Bromet, Hughes \& Nelson, 1995; Norris \& Kaniasty, 1994; Outcalt et al., 2015; Resnick, Kilpatrick, Dansky, Saunders \& Best, 1993; Ullman \& Siegel, 1996). Las investigaciones sugieren que quien ha estado involucrado en eventos traumáticos también puede sufrir de daños crónicos a la salud como hipertensión e infarto al miocardio (Baker, Norris, Jones \& Murphy, 2009; Dedert et al., 2010; Schnurr \& Green, 2004; Ullman \& Siegel, 1996).

La experiencia traumática durante un sismo puede ser extremadamente estresante y normalmente acompañada de reacciones fisiológicas intensas; los datos de estrés persistirán hasta que la persona evalúe que el reto ha pasado (Cohen \& Lazarus, 1973; Friedman \& Schnurr, 1995; Reynoso \& Seligson, 2005). En el TEPT, la persona es capaz de revivir el acontecimiento estresante en múltiples ocasiones, por lo tanto, es importante ofrecer acciones encaminadas a la reducción de este problema.

Se reportan algunos estudios post-terremoto en donde resalta la prevalencia de TEPT (19\% después de ocho meses del terremoto de 1985 en Chile [Durkin, 1993]). Tras el sismo de Armenia en 1988, la prevalencia era de 50\% a los dos años (Goenjian et al., 2000; Goenjian et al., 1994). Si bien, es cierto que los estudios no son comparables debido a los tamaños de la muestra y los instrumentos de evaluación utilizados, la relevancia de ello permite señalar la probabilidad de encontrar datos de TEPT en nuestra población en estos períodos.

Dadas las características en las que se suele presentar el TEPT y considerando la diversidad en las respuestas emocionales y conductuales que provoca, los objetivos deben ser: a) educar al paciente sobre la naturaleza e impacto de dicho malestar y b) asegurarles que la meta es prepararlo para la adquisición de ciertas habilidades que le permitan responder adaptativamente. Particularmente, entrenarlo para responder ante las respuestas derivadas de la interpretación, recurrencia y reacciones fisiológico-conductuales y emocionales asociadas al trauma (Williams \& Poijula, 2015).

En ese sentido, el entrenamiento se pone en marcha con miras a favorecer sensación de control sobre aquello que lo aqueja y no necesariamente para eliminar el trastorno. Todo ello no se puede realizar sin el uso de herramientas de evaluación y medición 
que permitan al psicólogo dimensionar la gravedad del problema y medir la magnitud del cambio a lo largo de la intervención. Desde el enfoque conductual y considerando que las respuestas desadaptativas se presentan como parte de las transacciones dinámicas entre el individuo y su ambiente, es necesario identificar no sólo la presencia de dichas respuestas sino también la funcionalidad que tienen en el paciente, por lo que se requiere de la elaboración de un análisis funcional de la conducta relacionada al TEPT. Si bien, la evaluación inicial y el diagnóstico del TEPT requiere de la verificación de comportamientos y síntomas para integrar un diagnóstico nosológico, desde la perspectiva conductual se requiere conocer de los eventos antecedentes y consecuentes que se presentan ante el evento traumático, para poder ofrecer alternativas de tratamiento adaptadas a cada paciente (Hanley, Iwata \& McCord, 2003). Un cuidadoso análisis de la información relacionada al paciente y las manifestaciones clínicas que nos hacen sospechar de la presencia de este trastorno nos llevará a la elaboración de un plan de intervención (Forteza \& Vara, 2000). De estos temas se hablará en el siguiente capítulo. 


\section{Capítulo 2}

\section{Evaluación conductual del TEPT}

\section{Entrevista conductual: recomendaciones para su uso en los individuos con TEPT}

Bajo la perspectiva cognitivo conductual, la evaluación de cualquier trastorno psicológico se enfoca en cómo las personas se comportan en situaciones particulares o en respuesta a varias contingencias de reforzamiento. Recordemos que el terapeuta de este enfoque asume que la interacción con el paciente es dinámica y bidireccional, pues el terapeuta colabora con el paciente en la identificación de la(s) conducta(s) problema (Villarreal, 1981; Morrison, 2015). Para ello, se vale de la conducta verbal para comunicarse y de la observación de las conductas presentadas por el paciente durante la entrevista (Becerra \& Reynoso, 2014).

Entonces, el primer elemento para identificar a las personas con TEPT requiere la aplicación de una entrevista semiestructurada que permita al clínico ubicar la existencia de la exposición a un evento traumático, la intensidad del malestar asociado al trauma y los intentos de solución previos. Por lo general, la entrevista conductual se desarrolla en un ambiente cordial, tranquilo, el terapeuta procura ganar la confianza del paciente, se establece rapport, se busca que el paciente pueda expresarse libremente y platicar inicialmente respecto del problema que le aqueja. Lo anterior puede constituir un impedimento dado que los pacientes evitan, en ocasiones, acudir a la consulta psicológica pues consideran escasa o nula la posible ayuda que el psicólogo podría ofrecerles, por lo 
que ser empático y mostrar interés genuino son elementos para lograr la permanencia y el compromiso del paciente con el trabajo terapéutico (Haynes \& O’Brien, 2003). Es frecuente que el paciente con TEPT se sienta solo y sin apoyo social, por ello, el terapeuta debe ofrecerle información respecto de su problema y proporcionar el soporte que tanto necesita.

Esta entrevista hace posible conocer detalles de la exposición al evento traumático, las respuestas cognitivas asociadas (recuerdos vividos y detallados, pensamientos e imágenes) las respuestas emocionales (ansiedad, ira, depresión o evitación), y lo más importante, permitirá hablar de las posibles causas y consecuencias derivadas del evento en un contexto funcional (Vargas \& Coria, 2017).

La guía de la entrevista dependerá del tipo de acontecimiento traumático y del daño que provocó en términos materiales y emocionales. En el caso de las catástrofes naturales, la evaluación inicial consistirá en la identificación de los individuos con mayor riesgo de sufrir los estragos y la identificación de apoyos locales para la adecuada canalización; sin embargo, pasados los días, la evaluación deberá incluir no sólo la entrevista sino escalas e inventarios de evaluación breves.

Para autores como San Juan (2001) y Williams y Poijula (2015) algunos elementos que deben considerarse dentro de la entrevista para ser indagados por el terapeuta son:

1. Datos generales del paciente. Será de importancia registrar datos relacionados a su aspecto físico general, su orientación en tiempo, espacio y persona, su repertorio verbal, la coherencia de sus respuestas, la latencia de éstas, la presencia de movimientos estereotipados, tics, etc. En el transcurso de la entrevista el terapeuta deberá observar comportamiento del entrevistado, además de la conducta verbal del mismo.

2. Historia médica. Información relacionada a los padecimientos, hospitalizaciones procedimientos médico-quirúrgicos a los que se ha sometido, y si el paciente se encuentra tomando medicamentos (ya que incluso pueden tener efectos en el comportamiento del paciente).

3. Historia psicológica. Datos relacionados a sus antecedentes psicológicos (diagnósticos previos, medicación, asistencia a consulta psiquiátrica o psicológica previa).

4. Detalles relacionados al evento traumático. Características generales del problema que le aqueja al paciente y cómo se ha desarrollado este problema a partir del 
evento traumático. Esta información puede ser breve o compleja, dependiendo del repertorio verbal del paciente y de la presencia de comorbilidades psicológicas o médicas.

5. Factores de riesgo asociados a la presencia del TEPT. Búsqueda de antecedentes de problemas emocionales en la infancia y antecedentes de trastornos del estado de ánimo. Indagar si sus estrategias de afrontamiento son predominantemente centradas en la emoción o evitativas.

6. Factores de protección asociados al TEPT. Identificar estilos y estrategias de afrontamiento funcionales y adaptativas previas al evento traumático, así como de información relacionada a las alternativas de apoyo para la solución de problemas. Es útil también conocer el tamaño de la red de apoyo y el tipo de apoyo que recibe por parte de familiares, amigos y otros miembros de la comunidad.

7. Verificar el cumplimiento de criterios nosológicos del TEPT y valorar la gravedad de los síntomas. Una vez identificado el TEPT debemos definir, con ayuda del paciente, la gravedad de los síntomas (motor, cognitivo-emocional, conductual y fisiológico) en diferentes parámetros conductuales posibles (latencia, intensidad, ocurrencia, duración y frecuencia).

8. Situaciones o condiciones que anteceden a las manifestaciones del TEPT. Identificar las condiciones estímulo externas (lugares, contextos, personas u objetos) como internas (recuerdos, cambios fisiológicos experimentados, imágenes intensas o vívidas) que anteceden o propician la presencia de malestar emocional.

9. Consecuencias que ocurren posterior al evento traumático y/o las manifestaciones del TEPT. Explorar el tipo de respuestas manifestadas posterior al evento traumático, así como las posibles condiciones que contribuyan en el mantenimiento del comportamiento desadaptativo.

10. Intentos de solución previos. ¿Qué se ha hecho al respecto? ¿Ha buscado ayuda profesional? ¿Ha tomado medicamentos?

11. Expectativas ante el tratamiento. Creencias e ideas relacionadas al cambio esperado, al trabajo realizado y las metas que pretendería lograr el paciente durante y posterior a la intervención. 


\section{Instrumentos de evaluación para el TEPT}

Como ya se ha mencionado, el TEPT aparece al término de un mes ocurrido el acontecimiento traumático, por lo que será necesario utilizar estrategias de evaluación que nos permitan obtener una historia detallada de la exposición al evento traumático. La entrevista debe acompañarse de la aplicación de inventarios para la identificación de este trastorno. Durante la aplicación se deberán ofrecer instrucciones claras sobre la forma de responderlo y si existe un tiempo límite, se deben aclarar las dudas o preguntas del paciente $y$, al igual que en la entrevista, no se deben sugerir las respuestas (Reynoso \& Seligson, 2005). Cuando el paciente entregue el inventario, se deberá verificar que ha sido respondido en su totalidad. En esta misma línea de evaluación, la Secretaría de Salud (2011) recomienda, a través de la Guía de práctica clínica. Diagnóstico y manejo del estrés postraumático, que el personal de salud calificado aplique instrumentos breves que permitan la detección del TEPT a un mes de haberse presentado el evento traumático (ya sea masivo o individual) y así comenzar con el tratamiento. Advierte que dichos programas de evaluación deben implementarse primordialmente en asilos o lugares de refugio para identificar a la población en riesgo y canalizar a instancias especializadas para su seguimiento. Meda, Moreno, Rodríguez, Arias y Palomera (2011) proponen utilizar la Escala de Estrés Traumático Secundario, validada en profesionales de emergencias médicas; Crespo y Gómez (2003) nos ofrecen los principales instrumentos de evaluación del TEPT y consideran además aquéllos que han sido traducidos al castellano, los cuales se presentan en la Tabla 2.1.

Una estrategia de gran utilidad en el modelo conductual consiste en la auto observación del comportamiento; por lo general, los pacientes no son capaces de señalar la intensidad, duración o frecuencia de sus comportamientos cotidianos. Para ayudar en la identificación de estos comportamientos, podemos valernos de autorregistros. Con este tipo de recursos podremos tener evidencia de: ¿Cuándo ocurre? ¿Cuántas veces? ¿En qué situaciones? ¿Qué factores se encuentran vinculados con su aparición? ¿Cuánto dura? ¿Cuándo cesa? ¿Por qué cesa? ¿Existen eventos incompatibles con la conducta en cuestión? (Ver Anexos 1 y 2 ).

Para identificar las situaciones antecedentes que propician las respuestas desadaptativas será necesario realizar con el paciente una reconceptualización de la vivencia del evento traumático. En esta misma línea, el uso de registros anecdóticos puede 
Tabla 2.1. Algunas escalas clínicas utilizadas para evaluar la presencia de TEPT

\begin{tabular}{|c|c|c|}
\hline $\begin{array}{l}\text { Prueba } \\
\text { Autores }\end{array}$ & Formato y contenido & $\begin{array}{l}\text { Adaptación } \\
\text { al español }\end{array}$ \\
\hline $\begin{array}{l}\text { Escala para el TEPT } \\
\text { administrada por el clínico } \\
\text { (CAPS-1 y CAPS-2) } \\
\text { Blake et al, } 1990\end{array}$ & $\begin{array}{l}\text { Entrevista } \\
3 \text { ítems naturaleza y repercusión del } \\
\text { acontecimiento } \\
17 \text { ítems (criterios B, C y D del DSM-IV) } \\
5 \text { síntomas asociados }\end{array}$ & $\begin{array}{l}\text { Bobes et al., } \\
2000\end{array}$ \\
\hline $\begin{array}{l}\text { Cribado breve para evaluar } \\
\text { TEPT } \\
\text { Breslau, Peterson, Ronald } \\
\text { \& Lonni, } 1999\end{array}$ & $\begin{array}{l}\text { Entrevista } \\
7 \text { ítems (criterios DSM IV) }\end{array}$ & $\begin{array}{l}\text { Rubio-Stipec, } \\
\text { Bravo \& } \\
\text { Canino, } 1991\end{array}$ \\
\hline $\begin{array}{l}\text { Cuestionario de experiencias } \\
\text { traumáticas (TQ) } \\
\text { Davidson, Hughes \& Blazer, } 1990\end{array}$ & $\begin{array}{l}\text { Cuestionario } \\
44 \text { ítems (criterios A, B, C y D del DSM-IV) }\end{array}$ & $\begin{array}{l}\text { Bobes et al., } \\
2000\end{array}$ \\
\hline $\begin{array}{l}\text { Escala de trauma de Davidson } \\
\text { (DTS) } \\
\text { Davidson et al., } 1997\end{array}$ & $\begin{array}{l}\text { Escala autoaplicada } \\
17 \text { ítems (criterios B, C y D del DSM-IV) }\end{array}$ & $\begin{array}{l}\text { Bobes et al., } \\
2000\end{array}$ \\
\hline $\begin{array}{l}\text { Escala de } 8 \text { ítems para los } \\
\text { resultados del tratamiento del } \\
\text { TEPT (TOP 8) } \\
\text { Davidson \& Colket, } 1997\end{array}$ & $\begin{array}{l}\text { Entrevista } \\
8 \text { ítems (síntomas criterios B, C y D del DSM-IV). } \\
\text { Los más sensibles al cambio. } \\
\text { Criterio B: recuerdos recurrentes e intrusivos y } \\
\text { respuestas fisiológicas } \\
\text { Criterio C: evitación, desapego, restricción de la } \\
\text { vida afectiva y reducción del interés } \\
\text { Criterio D: hipervigilancia y sobresalto exagerado }\end{array}$ & $\begin{array}{l}\text { Bobes et al., } \\
2000\end{array}$ \\
\hline $\begin{array}{l}\text { Entrevista estructurada para el } \\
\text { TEPT (SI-PTSD o SIP) } \\
\text { Davidson, Malick \& Travers, } 1997\end{array}$ & $\begin{array}{l}\text { Entrevista } \\
17 \text { ítems (criterios B, C, y D del DSM-IV) } \\
2 \text { ítems sobre culpabilidad }\end{array}$ & No \\
\hline $\begin{array}{l}\text { Índice global de Duke de } \\
\text { mejoría del TEPT (DRGP) } \\
\text { Davidson et al., } 1998\end{array}$ & $\begin{array}{l}\text { Escala heteroaplicada } \\
4 \text { ítems: valoración de efectos del tratamiento } \\
\text { (los tres criterios de síntomas del DSM-IV y uno } \\
\text { de evaluación global }\end{array}$ & $\begin{array}{l}\text { Bobes et al., } \\
2000\end{array}$ \\
\hline
\end{tabular}




\section{Prueba}

Autores

\section{Formato y contenido}

Adaptación

al español

\begin{tabular}{|c|c|c|}
\hline Adis-R PTSD & Entrevista & \multirow{2}{*}{ No } \\
\hline Di Nardo \& Barlo, 1988 & 17 ítems (síntomas DSM-IV criterios B, C y D) & \\
\hline $\begin{array}{l}\text { Escala de gravedad de síntomas } \\
\text { del TEPT } \\
\text { Echeburúa et al., } 1997\end{array}$ & $\begin{array}{l}\text { Entrevista } \\
17 \text { ítems (criterios B, C y D del DSM-IV) } \\
\text { Subescala de síntomas psicofisiológicos del } \\
\text { ataque de pánico }\end{array}$ & No \\
\hline $\begin{array}{l}\text { Modified PTSD symptom scale } \\
\text { self-report (MPSS-SR) } \\
\text { Falsetti et al., } 1993\end{array}$ & $\begin{array}{l}\text { Escala autoaplicada } \\
17 \text { ítems (criterios B, C y D del DSM-IV) } \\
\text { Frecuencia y nivel de angustia de cada síntoma }\end{array}$ & No \\
\hline $\begin{array}{l}\text { Posttraumatic stress diagnostic } \\
\text { scale (PDS) } \\
\text { Foa, } 1995\end{array}$ & $\begin{array}{l}\text { Cuestionario } \\
49 \text { ítems (criterios A, B, C, D, E y F del DSM-IV) }\end{array}$ & No \\
\hline $\begin{array}{l}\text { Posttraumatic cognitions } \\
\text { inventory (PTCI) } \\
\text { Foa et al., } 1999\end{array}$ & $\begin{array}{l}\text { Inventario } \\
36 \text { ítems (cogniciones negativas sobre uno } \\
\text { mismo, sobre el mundo y autoinculpación) }\end{array}$ & $\begin{array}{l}\text { Labrador \& } \\
\text { Rincón, } 2003\end{array}$ \\
\hline $\begin{array}{l}\text { Potential stressful events } \\
\text { interview (PSEI) } \\
\text { Killpatrick, Resnick \& Freedy, } 1991\end{array}$ & $\begin{array}{l}\text { Entrevista } \\
\text { Tipo de estresor y cualidades de éste } \\
15 \text { ítems sobre reacciones subjetivas }\end{array}$ & No \\
\hline $\begin{array}{l}\text { Traumatic life events interview } \\
\text { (TLEI) } \\
\text { Kubany, } 1995\end{array}$ & $\begin{array}{l}\text { Entrevista } \\
\text { Historia de aconteciminetos traumáticos (17 } \\
\text { ítems) } \\
\text { Presencia/ausencia, frecuencia y descripción }\end{array}$ & No \\
\hline $\begin{array}{l}\text { Trauma-related guilt inventory } \\
\text { (TRGI) } \\
\text { Kubany et al., } 1996\end{array}$ & $\begin{array}{l}\text { Cuestionario } \\
32 \text { ítems (malestar y cogniciones de culpa) }\end{array}$ & No \\
\hline $\begin{array}{l}\text { Distressing event questionnaire } \\
\text { (DEQ) } \\
\text { Kubany et al., } 2000 a\end{array}$ & $\begin{array}{l}\text { Cuestionario } \\
34 \text { ítems (criterios A2, B, C, D y F del DSM-IV) y } \\
\text { síntomas asociados (culpa, cólera y dolor) }\end{array}$ & No \\
\hline $\begin{array}{l}\text { Traumatic life events } \\
\text { questionnnaire (TLEQ-2) } \\
\text { Kubany et al., 2000b }\end{array}$ & $\begin{array}{l}\text { Cuestionario } \\
16 \text { acontecimientos traumáticos más otro no } \\
\text { especificado }\end{array}$ & No \\
\hline
\end{tabular}


Prueba

Autores

Formato y contenido
Adaptación

al español

Instrumento de cribado para el
TEPT (SPAN)
Meltzer-Brody, Churchill \&
Davidson, 1999

Cuestionario de cribado

4 ítems (criterios DSM-IV)

respuestas fisiológicas a la exposición (criterio $B$ )

Restricción vida afectiva (criterio C)

Irritabilidad (criterio D)

Sobresalto exagerado (criterio D)

Entrevista

Harvard trauma questionnaire

(HTQ)

Mollica et al., 1992
17 ítems (síntomas DSM-IV, criterios B, C y D)

Otros síntomas de estrés (experimentados por

No

refugiados de Indochina)

\begin{tabular}{|c|c|c|}
\hline $\begin{array}{l}\text { Personal beliefs and reactions } \\
\text { scale (PBRS) } \\
\text { Resick, } 1993\end{array}$ & $\begin{array}{l}\text { Cuestionario } \\
55 \text { ítems (diseñados para víctimas de violación) }\end{array}$ & No \\
\hline $\begin{array}{l}\text { Structured clinical interview for } \\
\text { DSM-IV (SCID-PTSD) } \\
\text { Spitzer et al., } 1990\end{array}$ & $\begin{array}{l}\text { Entrevista } \\
19 \text { ítems (criterios del DSM-IV) }\end{array}$ & No \\
\hline $\begin{array}{l}\text { Traumatic events questionnaire } \\
\text { (TEQ) } \\
\text { Vrana \& Lauterbach, } 1994\end{array}$ & $\begin{array}{l}\text { Cuestionario } \\
11 \text { acontecimientos traumáticos mas otro no } \\
\text { descrito }\end{array}$ & No \\
\hline $\begin{array}{l}\text { The PTSD checklist-civilian } \\
\text { version (PCL-C) } \\
\text { Weathers et al., } 1996\end{array}$ & $\begin{array}{l}\text { Escala autoaplicada } \\
17 \text { ítems (criterios B, C y D del DSM-IV) } \\
\text { Presencia/ausencia y gravedad de cada síntoma }\end{array}$ & No \\
\hline $\begin{array}{l}\text { Escala revisada del impacto del } \\
\text { acontecimiento (IES-R) } \\
\text { Weiss \& Marmar, } 1996\end{array}$ & $\begin{array}{l}\text { Escala autoaplicada } \\
17 \text { ítems (criterios B, C y D del DSM-IV) }\end{array}$ & No \\
\hline $\begin{array}{l}\text { Entrevista estructurada DSM-IV } \\
\text { Zimmerman, } 1994\end{array}$ & $\begin{array}{l}\text { Entrevista } \\
\text { Criterios DSM-IV (A, B, C, D, E y F) }\end{array}$ & No \\
\hline $\begin{array}{l}\text { Cuestionario para evaluar TEPT } \\
\text { Moreno, Morante, Rodríguez \& } \\
\text { Garroza, } 2004\end{array}$ & $\begin{array}{l}\text { Escala autoaplicada } \\
14 \text { ítems con } 4 \text { opciones de respuesta }\end{array}$ & $\begin{array}{l}\text { Meda-Lara, } \\
\text { Moreno, } \\
\text { Rodríguez, } \\
\text { Ariasy } \\
\text { Palomera, } 2011\end{array}$ \\
\hline
\end{tabular}

Nota: Modificado de "Propuesta de un inventario para la evaluación y diagnóstico de estrés post traumático", M. Crespo y M.M. Gómez, 2003, Psicopatología Clínica, Legal y Forense, 3(3), pp. 46-47. 
ayudarnos a apreciar la forma en cómo el paciente lo interpreta y cómo a su vez lo incorpora a su repertorio de comportamientos actuales. La ubicación del contexto y la medición de las respuestas en parámetros de intensidad y frecuencia darán cuenta del cambio terapéutico a lo largo del tiempo. Para ello, hay que señalar al paciente la forma de registrar, ofreciendo ejemplos y entregándole formatos de registro (Meichenbaum, 1987; Meichenbaum, 2017).

\section{Análisis funcional del comportamiento relacionado al TEPT}

El término análisis funcional fue utilizado inicialmente por Skinner (1953) para señalar la existencia de relaciones entre el ambiente y la conducta. En este contexto, el análisis funcional describe una relación entre el evento traumático y las respuestas fisiológicas, conductuales, cognitivasy emocionales. Su objetivo radica en identificarlos determinantes de la conducta y los tratamientos efectivos que produzcan resultados generalizados. Aunque existen criterios nosológicos que delimitan la presencia del TEPT, las formas en que se presentan las respuestas en los pacientes son individuales y únicas, por lo tanto, es indispensable efectuarlo para conocer cada uno de los aspectos relacionados al evento traumático (variables contextuales, variables relacionadas al organismo, variables que obedecen a la presencia e intensidad del malestar, etc.), esto con la finalidad de buscar un resultado a corto plazo que sea observable y medible para el mismo paciente. Recordemos también que los pacientes que presentan TEPT no siempre tienen reacciones predecibles y ordenadas (particularmente después del evento traumático) y, en consecuencia, no necesariamente se puede disponer de información que sugiera las pautas a seguir ante la evolución del trastorno, por lo que un análisis individual dará luz para iniciar con la intervención (Carr, 1994).

Se ha demostrado que un adecuado análisis de las causas que mantienen las conductas problema es esencial para diseñar estrategias de intervención particulares para cada persona. Si se identifican las contingencias que mantienen las conductas problema, las consecuencias relevantes y sus estímulos discriminativos asociados, las manifestaciones comportamentales relacionadas al TEPT pueden ser modificadas $\mathrm{y} / \mathrm{o}$ eliminadas (por ejemplo: comportamiento irritable, arrebatos de furia, comportamiento imprudente o autodestructivo, ausentismo laboral, aislamiento, evitar actividades, lugares, personas, conversaciones relacionadas al evento traumático, consumo de alcohol y tabaco, así como uso de drogas lícitas o ilícitas). 
Turk, Meichenbaum y Genest (citados en Meichenbaum, 1987) consideran que las etapas para obtener una evaluación analítica del comportamiento son básicamente:

1. Identificar el problema.

2. Enumerar/cuantificar las respuestas que presenta el paciente.

3. Evaluar las respuestas en términos de la variabilidad en el tiempo y posterior al entrenamiento.

Identificar cada uno de estos elementos permitirá al psicólogo reconocer las manifestaciones del problema no sólo a nivel morfológico sino también funcional. En la Figura 2.1. se ilustra un esquema sistemático para identificar de forma clara los elementos asociados a las respuestas que se producen en los pacientes con TEPT.

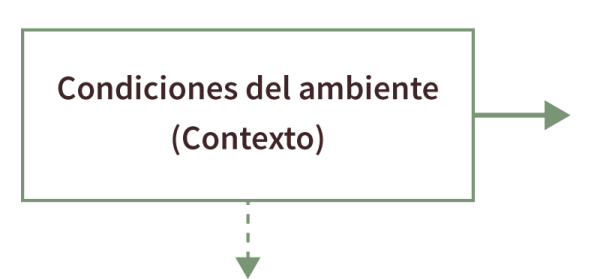

Evento traumático

(Ambiente)

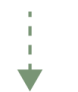

Estímulo(s) evocador (es)

de las respuestas problema

(Valoración del entorno y las

posibles respuestas que anteceden)

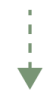

Acontecimientos históricos

¿Ya se enfrentó a una condición similar?

¿De qué estrategias dispuso para resolver/

enfrentar dicho evento? ¿Funcionó?

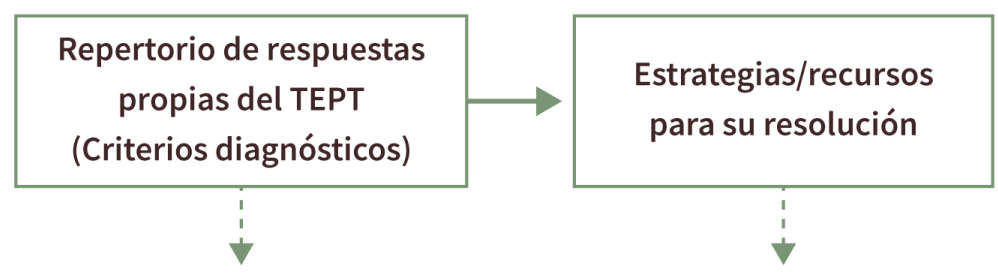

Respuestas motoras, cognitivas o fisiológicas (asociadas al evento traumático)
Comportamientos emitidos por el paciente o por otros que ocurren posterior a las respuestas propias del trastorno

Condiciones que contribuyen al mantenimiento/resolución del trastorno

Figura 2.1. Elementos por considerar en la elaboración del análisis funcional de la conducta en un paciente con TEPT.

\section{Indicadores para la adecuada canalización multidisciplinaria del paciente}

Ciertos estilos de personalidad o antecedentes de trastornos relacionados a la ansiedad y la depresión, pueden ser factores predisponentes al TEPT o pueden funcionar como 
agravantes en el curso del mismo (SSA, 2011). La presencia de alguna comorbilidad psiquiátrica puede provocar un incremento de las respuestas disfuncionales provocadas por el TEPT. Los pacientes con trastorno de depresión tienen un mayor riesgo de presentar problemas de ajuste y mayor tendencia a la recaída. En estos casos, se debe canalizar al paciente a profesionales autorizados para prescribir medicamentos. El plan terapéutico psiquiátrico para el TEPT puede incluir el uso de fármacos (como los inhibidores selectivos de la recaptura de serotonina). Sin embargo, se recomienda que el tratamiento psicológico sea paralelo para mayores resultados (APA, 2006; Hetrick, Purcell, Garner y Parslow, 2010). En el caso de los pacientes que suman al TEPT, síntomas psicóticos o de agresividad debe agregarse tratamiento farmacológico a dosis ajustadas. La ruta crítica para la toma de decisiones en el tratamiento se presenta en la Figura 2.2.

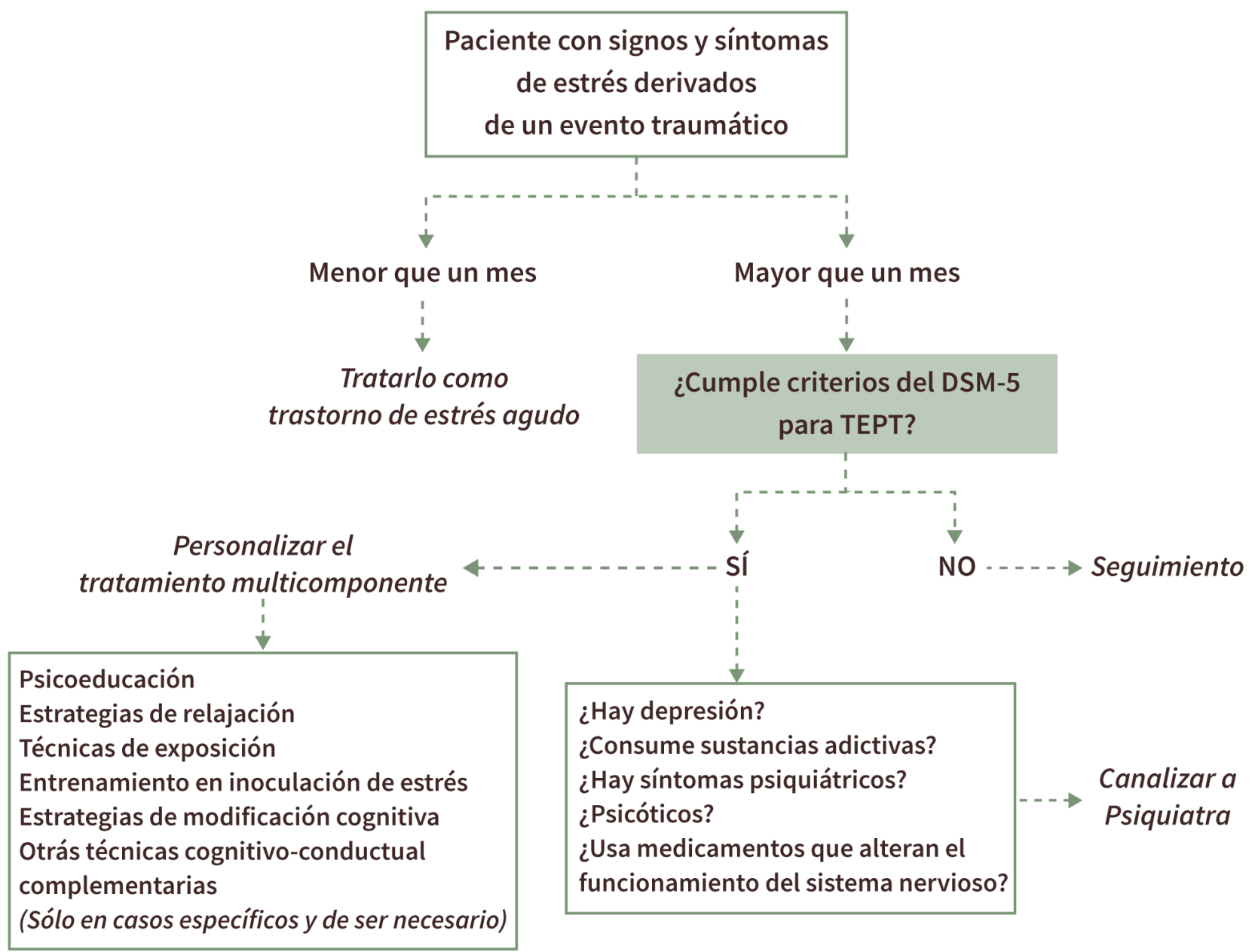

Figura 2.2. Ruta crítica para la toma de decisiones en el tratamiento del TEPT. 
Como puede notarse, identificar la presencia del TEPT puede resultar complejo y va más allá del simple cumplimiento de criterios nosológicos. El proceso de evaluación en ese sentido debe ser estructurado, pero flexible y, sobre todo, debe incluir el trabajo de otros especialistas de la salud. De cualquier forma, si se trata de un tratamiento psicológico o integral (que incluya la intervención de otros expertos), se recomienda enseñar al paciente que los cambios tomarán tiempo y se requiere de acciones muy concretas de su parte para tener efectos positivos posteriores al entrenamiento. Se recomienda, también, señalar que debe cumplir con las recomendaciones médicas (sobre todo si padece de una enfermedad crónica o si debe consumir ansiolíticos u otro tipo de medicamento prescrito por el psiquiatra) evitando en gran medida la automedicación o el abandono del tratamiento. 


\section{Capítulo 3}

\section{Técnicas de intervención cognitivo-conductual para el TEPT}

El entrenamiento enfocado en la modificación de respuestas desadaptativas relacionadas al TEPT debe incluir estrategias encaminadas a la identificación y modificación de mecanismos de pensamiento asociado al evento traumático, así como al control de respuestas fisiológicas y conductuales que impiden el cese de la respuesta de miedo condicionada por los recuerdos asociados al mismo (Astin \& Resick, 2006). Si bien, es cierto que las manifestaciones del TEPT son individuales y únicas, el cumplimiento de los criterios nosológicos opera de la misma manera en los pacientes, por lo que no podría descartarse el entrenamiento grupal como una opción de tratamiento (Vargas \& Coria, 2017).

Las técnicas de intervención que a continuación se describen están basadas en evidencia y resultan ser elementos primordiales para el tratamiento de este trastorno en distintas guías de práctica clínica nacionales e internacionales. Estos documentos señalan que la intervención psicológica (también denominada tratamiento no farmacológico) funciona como sustento principal para el control de las respuestas cognitivas, conductuales y fisiológicas asociadas al TEPT. Dichas técnicas de intervención descansan bajo la Terapia Cognitivo-Conductual (TCC), ya que es el modelo que ha probado tener la mayor efectividad para el control del TEPT y prevenir las recaídas (American Psychological Association [APA], 2017; Dobson \& Dobson, 2009; Labrador \& Crespo, 2012; SSA, 2011). 
Para iniciar este capítulo, debemos considerar algunas cuestiones. Primero, es necesario tener claro que para llevar a cabo la intervención en personas que estuvieron expuestas a un evento traumático, es primordial conocer y plantear las condiciones adecuadas para garantizar que la persona que recibirá el apoyo se encuentre fuera de peligro, contar con la vía para canalizarla a instancias pertinentes que proporcionen apoyo legal, de alojamiento, de la salud para la valoración médica oportuna y, una vez hecho esto, el psicólogo deberá concentrarse en la evaluación y la elección de la forma de intervención más adecuada para el caso de cada persona (Galindo, 2010). Dadas las características del TEPT y su severidad, el tratamiento psicológico debe iniciarse en los primeros meses del evento traumático como un proceso breve, con base en los postulados de la TCC ( 8 a 12 sesiones, una por semana) (APA, 2017). Debe tomarse en cuenta el tiempo transcurrido entre el evento traumático y el comienzo de los síntomas, así como las afectaciones funcionales y en la calidad de vida (APA, 2013). Finalmente, es necesario aclarar que la duración del tratamiento debe determinarse considerando el compromiso y actuar del paciente y no en un número de sesiones predeterminado, es decir, si durante cada una de las fases del entrenamiento se observa que el paciente presenta complicaciones ante la ejecución, es deber del terapeuta reeducar y retroalimentar ante las fallas o dudas (Persons, 2008).

Ahora bien, en lo que respecta a las estrategias de intervención bajo las cuales se dirige el tratamiento, las que más se utilizan para controlar las respuestas derivadas del trauma y atenuar las respuestas relacionadas al estrés son: 1) técnicas de relajación (activa o pasiva); 2) técnicas conductuales de exposición; 3) técnicas de autocontrol; 4) entrenamiento en solución de problemas; 5) técnicas para la modificación de cogniciones; 6) entrenamiento en habilidades sociales; y 7) psicoeducación a lo largo del proceso terapéutico (APA, 2006; 2017; Astin \& Resick, 2006; Bolton et al., 2004; Meadows \& Foa, 1999; SSA, 2011).

Estas técnicas se orientan a cumplir objetivos finales como mejorar el funcionamiento general y la calidad de vida, y particularmente se centrarán en: a) una disminución de la activación fisiológica; b) modificar la respuesta cognitiva derivada de la valoración de la amenaza; c) desensibilizar al paciente frente a los desencadenantes relacionados con el evento traumático; y d) mejorar las estrategias de afrontamiento ante los eventos experimentados (Nezu, Nezu \& Lombardo, 2006; Nezu \& Nezu, 2008). 
El curso general de la intervención comienza proporcionando información sobre las respuestas que caracterizan al TEPT, así como, de la funcionalidad que tienen sus comportamientos, emociones y pensamientos desde que se presentó el acontecimiento traumático. Una vez que el terapeuta haya evaluado la capacidad del paciente para tolerar la ansiedad se puede entrenar al paciente en ejercicios de relajación (Foa, Steketee \& Grayson, 1985). La exposición puede, en algunas ocasiones y dependiendo de las estrategias de afrontamiento del paciente, funcionar como un estímulo evocador de respuesta emocional en lugar de reducirla, por lo que el terapeuta deberá tomar precauciones (Lancaster, Melka, Rodríguez \& Bryant, 2014).

Posteriormente, prever la ocurrencia de recaídas en el futuro es fundamental, ya que la intensidad del malestar tiende a incrementar con el tiempo, particularmente cuando el terapeuta ya no está realizando actividades de intervención y dirección. Se puede prevenir la recaída a través de programas que enseñen a los pacientes estrategias para identificar y afrontar el problema de la recaída; se implementa un programa psicoeducativo.

El modelo de prevención de recaída puede ser entendido, de acuerdo con Marlatt, como un proceso que facilita cambios en los hábitos personales y en el estilo de vida y de esta forma reduce el riesgo de estrés. Se parte de la base que la persona experimenta una sensación de control percibido cuando ha logrado-momentáneamente-sumeta. Mientras mayor sea el período de control, mayor la percepción de autocontrol. Esta precepción continúa hasta que la persona se encuentre con una situación de alto riesgo (situación que amenace la sensación de control de la persona e incremente la probabilidad de recaída). Marlatt identificó tres categorías principales: 1 ) estados emocionales negativos: situaciones en las que la persona experimenta un estado emocional negativo o no placentero como frustración, enojo, ansiedad o depresión; 2) conflicto interpersonal, que implica la dificultad en una relación interpersonal (entre amigos, familiares, o relaciones empleado-empleador); 3) presión social: situaciones en las que la persona responde a la influencia de otra persona o grupo que ejerce presión (directa o indirecta) sobre él (Marlatt \& George, 1984; Marlatt \& Donovan, 2005).

Otra razón por la cual se presentan las recaídas es porque los pacientes suelen atribuir su malestar a respuestas inalterables, por un bajo control de los contratiempos y la suma de nuevos acontecimientos que pueden provocar respuestas de estrés agudo. En 
ese sentido, el terapeuta debe incorporar en el plan de intervención elementos que contribuyan al incremento de la autoeficacia del paciente $y$, por supuesto, dar seguimiento y refuerzo ante las posibles complicaciones mediatas (Nezu et al., 2006).

Para prevenir las recaídas se deben identificar situaciones de alto riesgo en las cuales el individuo es vulnerable a recaer y entonces utilizar estrategias de afrontamiento para prevenirlas. La prevención de las recaídas puede ser descrita como una forma de prevención terciaria con dos propósitos concretos: a) prevenir la recaída y b) proveer herramientas para manejar la recaída si ésta ocurriese.

A continuación, se presenta una descripción de cada una de las técnicas psicológicas que forman parte del tratamiento para el TEPT, desde la TCC.

\section{Psicoeducación}

La psicoeducación es una forma de intervención para proporcionar a los pacientes un enfoque teórico y práctico que les permita identificar las características de un trastorno o problema psicológico y afrontar las consecuencias. El papel de la psicoeducación es ofrecer información que posibilite el cambio conductual, además de implicar cooperación activa y la puesta en marcha de ejercicios y actividades entre el terapeuta, pacientes y sus familias (Bäuml, Froböse, Kraemer, Rentrop \& Pitschel-Walz, 2006). La psicoeducación cumple diversas funciones (Zayfert \& Black-Becker, 2008):

1. Ofrecer información sobre el TEPT para orientar las expectativas de los pacientes sobre el tratamiento.

2. Ofrecer una estructura clara sobre el tratamiento, lo cual favorece que el paciente y sus familiares colaboren activamente y de manera informada.

3. La información proporcionada permite al paciente revaluar y procesar los recuerdos traumáticos.

4. La información ayuda a que los pacientes entiendan y clarifiquen sus reacciones a los sucesos traumáticos, es decir, que estas son normales y existe explicación lógica para lo que experimentan.

En esta lógica, la psicoeducación se orienta, por un lado, en la organización, estructura y componentes de la intervención, y por otro, en el análisis y comprensión de las reacciones comunes entre quienes enfrentaron un evento traumático. Con relación al 
último punto, resulta de gran relevancia que esta técnica incorpore la perspectiva de los pacientes sobre lo que vivieron y continúan experimentando, para que así tenga sentido para ellos (Bäuml et al., 2006; Nezu et al., 2006; Sin, Spain, Furuta, Murrells \& Norman, 2017; Zayfert \& Black-Becker, 2008).

La intervención psicoeducativa normalmente es conducida por el especialista y se recomienda que lo realice a través de diferentes formatos, como son: 1) ofrecer información verbal, que incluya la práctica de actividades; 2) información impresa, como libros, trípticos o manuales informativos; 3 ) información audiovisual, entre los que destacan talleres, audios, videos informativos o sitios web (Bennett, 2004; Ritz, Meuret, Trueba, Fritzschey \& von Leupoldt, 2013; Tousman, Zeitz, Taylor \& Bristol, 2007). En la Tabla 3.1. se observan algunos elementos informativos que deben considerarse en el proceso psicoeducativo del TEPT con el paciente y su familia.

Tabla 3.1. Descripción de elementos fundamentales en la intervención psicoeducativa con pacientes con TEPT y sus familias

\section{Psicoeducación}

- Información relacionada al TEPT y sus diferentes manifestaciones (sin dar énfasis al diagnóstico, pero explicitando la funcionalidad evitativa que resulta de este tipo de respuestas)

- Información relacionada a los eventos de carácter traumático y su control e incertidumbre (desastres naturales)

- Información del modelo cognitivo-conductual

- Explicación del funcionamiento individual ante el problema (Análisis Funcional de la Conducta)

- Explicación relacionada a las metas del tratamiento y objetivos a lograr con el paciente

- Información verbal e ilustrada de las diferentes técnicas a implementar y sus alcances en el control de los síntomas

- Información relacionada al uso de autorregistros y tareas en casa

- Información y recomendaciones para el control de recaídas ante lo impredecible que resulta un desastre natural (sismo)

- Información relacionada a los planes de acción y centros de apoyo de presentarse un sismo nuevamente 
Como se puede observar, la psicoeducación es un elemento fundamental en cualquier momento de la intervención, sin embargo, debe evitarse que el paciente a lo largo de este proceso se sobreinforme o consulte fuentes de información poco confiables (Tabla 3.2.).

\section{Tabla 3.2. Psicoeducación: consideraciones para su aplicación}

\section{Psicoeducación}

- Proporcionar información sobre un problema y el tratamiento, con

Objetivo el propósito de reducir el estrés, delimitar expectativas, clarificar reacciones y construir una base lógica para los problemas que se viven

- Determinar qué información es relevante y pertinente

- La información debe ser clara, concisa y sencilla

Elementos a - Pedir retroalimentación al paciente para comprobar que entiende considerar correctamente la información

- Proporcionar la información por escrito

- Implementar estrategias para la acción

Elementos a considerar para no aplicar la - No utilizar la técnica si el paciente está sobreinformado técnica

La psicoeducación también resulta necesaria para la introducción, justificación y descripción de las diferentes técnicas que constituyan el tratamiento.

\section{Estrategias para favorecer la relajación}

El entrenamiento en relajación resulta de utilidad para disminuir la activación fisiológica experimentada a causa del TEPT. El entrenamiento en estrategias de relajación como la respiración diafragmática favorece cambios en el corto plazo, pues el efecto que tiene la respiración provoca estimulación vagal y, en consecuencia, se genera la relajación como estado incompatible a la tensión con la que viven los pacientes (Barret, Boitano, Barman \& Brooks, 2010; Bernstein, Borkoveck \& Hazlett-Stevens, 2000).

El entrenamiento en relajación es gradual, ajustado a las necesidades del paciente y funciona como una estrategia de afrontamiento activa que requiere no sólo de un entrenamiento eficaz, sino también de una práctica continua, en horarios, 
lugares y situaciones específicas, por lo que se debe psicoeducar sobre la expectativa de cambio. La idea radica en enseñar a conocer las formas en que el cuerpo responde ante determinadas circunstancias, pero sobre todo a tener un dominio de aquello que cognitivamente y fisiológicamente le aqueja, examinando las consecuencias derivadas de dichas respuestas y su relación con otras variables como las emocionales y conductuales (Scotland-Coogan \& Davis, 2016).

A este respecto, el entrenamiento en relajación no busca la eliminación completa de los niveles de activación fisiológica (ya que esto simplemente no es posible), pero se puede lograr un mejor equilibrio y autoconocimiento y disminuyendo las respuestas de estrés, la tensión muscular, frecuencia cardiaca, tensión arterial y la frecuencia respiratoria, para así afrontar de mejor manera (en términos fisiológicos y conductuales) acontecimientos y eventos amenazantes posteriores (Scotland-Coogan \& Davis, 2016; Vázquez, 2001).

\section{Respiración}

El entrenamiento en relajación basados en la regulación de la respiración y la relajación de tipo pasiva requiere inicialmente de una fase de presentación de la técnica donde se expliquen los fundamentos, objetivos y pasos a seguir. Posteriormente, se presentan las recomendaciones para la respiración, que en general son la siguientes (Lancaster, Teeters, Gros \& Back, 2016; Scotland-Coogan \& Davis, 2016; Vázquez, 2001):

1. La inspiración debe llevarse a cabo por la nariz.

2. La respiración debe tener un ritmo lento (sin forzar la inspiración y procurando una intensidad de respiración habitual).

3. La inspiración constituye la fase activa y la espiración es pasiva.

4. El paciente debe concentrarse en las sensaciones corporales que experimenta durante los ejercicios respiratorios.

\section{Relajación muscular progresiva}

Otra alternativa que se emplea en el control de las respuestas de estrés y ansiedad es la relajación muscular progresiva. Este entrenamiento favorece la reducción de los niveles de activación por medio del control progresivo y voluntario de la tensión muscular. Por ello, el paciente debe de ser capaz de discriminar entre sensaciones de tensión y 
relajación muscular. Cabe señalar que este tipo de entrenamiento puede incluir ejercicios de respiración e imaginación (Vázquez, 2001).

De manera general, el procedimiento de aplicación del entrenamiento incluye las siguientes etapas (Bernstein et al., 2000; Vázquez, 2001):

1. Presentación de la técnica y entrenamiento inicial: esta etapa consta de una sesión en la que, encontrándose en un contexto físico favorable, se ofrece psicoeducación sobre el entrenamiento, identificación de estados de tensión-distensión muscular, ejercicios breves de tensión-distensión de algunos grupos musculares, evaluación e identificación de los efectos relajantes de la práctica y tareas para casa.

2. Consolidación del entrenamiento: en la que se llevan a cabo una serie de prácticas a lo largo de ocho sesiones (o en función de los avances del paciente) en las que se trabaja de manera completa en la tensión-distensión muscular a lo largo de todos los grupos musculares (manos y antebrazos, bíceps, tríceps, frente, boca, mandíbula, nuca, pecho, espalda, abdomen, glúteos, piernas, pantorrillas y pies). Cabe destacar que de esta etapa se desprenden dos subetapas: a) entrenamiento intermedio en el que al irse consolidando el entrenamiento se puede reducir gradualmente el tiempo de práctica con base en la tensión y distensión únicamente de siete grupos musculares; y b) entrenamiento avanzado en el que se centra la tensión-distensión en únicamente cuatro grupos musculares.

3. Relajación por evocación: para esta etapa el paciente ya es capaz de relajarse tensando y destensando únicamente cuatro grupos musculares, y por ello, se procede a favorecer la relajación sin tensar los músculos (vinculado a los dos procedimientos de relajación previamente descritos).

4. Relajación por evocación y recuerdo: en esta etapa se espera que la relajación se logre con apoyo de frases específicas que hagan referencia a los estados de relajación ya conocidos y dominados, dichas frases deben conjugarse con ejercicios de respiración.

\section{Imaginación guiada}

La imaginación guiada se centra en cómo las personas pueden crear experiencias sensoriales internas, en ausencia de un estímulo externo que las genere (Johnsen \& Lutgendorf, 2001) y en cómo estas experiencias pueden producir cambios fisiológicos (Epstein et al., 
2004). Se caracteriza por ser una estrategia de relajación basada en la visualización de imágenes y escenas con componentes auditivos, olfatorios, kinestésicos y propioceptivos (Johnsen \& Lutgendorf, 2001; Louie, 2004; Overholser, 1991).

La imaginación guiada se realiza inicialmente con la ayuda y guía del terapeuta, aunque se puede realizar una grabación en audio acompañada por sonidos de tonalidades lentas y bajas, y se recomienda una duración entre 10 y 30 minutos (Cooper \& Stollings, 2010; Epstein et al., 2004; Louie, 2004; Meadows \& Foa, 1999; Overholser, 1991).

Con base en las descripciones de Overholser (1991), Epstein et al. (2004), Louie (2004) y Cooper y Stollings (2010), el protocolo de imaginación guiada normalmente incluye el siguiente proceso:

1. Se lleva a cabo con el paciente recostado en una posición cómoda y en un lugar tranquilo.

2. Se pide al paciente que cierre sus ojos lentamente, que se concentre en su respiración invitándolo a tratar de estar en calma.

3. Posteriormente, se le pide que se concentre en diversas sensaciones, lo más claro y vívido que se pueda.

Como se puede observar, estos procedimientos combinan estrategias para favorecer la relajación y la evocación de imágenes y sensaciones, estas últimas pueden ser genéricas y de preferencia construidas a partir de la experiencia de cada paciente, así como con características contextuales relevantes y que se relacionen con las situaciones y condiciones en donde se desea favorecer las estrategias de afrontamiento funcionales.

Derivado de la práctica de esta estrategia se espera que se produzcan una serie de cambios fisiológicos, por ejemplo: a) disminución de las cifras de tensión arterial; b) reducción de la frecuencia cardiaca; c) decremento en la frecuencia respiratoria; d) aumento en la respiración profunda; y e) aumento en la relajación muscular (Bernstein et al., 2000; Louie, 2004; Vázquez, 2001).

La imaginación guiada parece ser funcional para el tratamiento del TEPT, al menos en lo que respecta a la reducción de la actividad fisiológica; sin embargo, se debe recordar que uno de los principales elementos que configura el TEPT es la frecuente presencia de recuerdos o imágenes vividas intensamente, por lo que recomendamos tener cautela con esta técnica. El uso de imágenes no siempre puede resultar de utilidad, particularmente 
si no se tiene cuidado con el tipo de imágenes a evocar por el paciente. Si no se tiene un conocimiento claro de los antecedentes del paciente se puede caer en el riesgo de incrementar la respuesta desadaptativa, perpetuando el problema por simple contracondicionamiento. Desde una perspectiva fisiológica, la ansiedad se origina y mantiene por los procesos fisiológicos de activación del sistema nervioso simpático, con lo que es posible explicar el incremento de la frecuencia cardiaca, la palidez, el temblor y la rigidez muscular, entre otros síntomas y la respuesta de relajación, que implica respiración profunda, entre otras estrategias, supone la activación del sistema parasimpático; ambos sistemas forman parte del sistema nervioso autónomo y sus funciones son antagónicas con el propósito de mantener un equilibrio dinámico denominado homeostasis (Reynoso, s.f.). La imaginación guiada supone un contracondicionamiento, es decir, el condicionamiento del estímulo ansiógeno a la respuesta incompatible. Además, las técnicas de respiración y relajación son más fácilmente aceptadas en los pacientes, sobre todo cuando experimentan fuertes sensaciones y malestar fisiológico. No obstante, si se ha realizado una evaluación adecuada del paciente, es posible trabajar con esta técnica como parte del tratamiento en pacientes TEPT (Lahad \& Doron, 2006; Meadows \& Foa, 1999).

Lo anterior, se sustenta en estudios en los que la imaginación guiada resulta de utilidad en el manejo de sintomatología de TEPT, depresión, calidad de vida a nivel psicológico, hostilidad y cinismo, en combatientes activos de fuerzas armadas (Jain et al., 2012), y en sintomatología general de TEPT, evitación, intrusión, hipervigilancia, calidad del sueño, bienestar general y funcionamiento social, siendo la hipervigilancia, el bienestar y el funcionamiento social las áreas de mayor mejoría; esto en personas refugiadas por conflictos armados (Beck et al., 2018). Para la revisión de algunos ejemplos, consultar Anexo 3 sobre estrategias de respiración/relajación y entrenamiento en imaginación guiada.

De aplicar la imaginación guiada, el terapeuta deberá tener cuidado, ya que la respuesta emocional durante la práctica puede ser adversa y no se logrará el objetivo que se persigue con esta técnica (Tabla 3.3.). 
Tabla 3.3. Psicoeducación: consideraciones para su aplicación

\begin{tabular}{|c|c|}
\hline \multicolumn{2}{|c|}{ Imaginación guiada } \\
\hline Objetivo & $\begin{array}{l}\text { - Controlar emociones y sensaciones internas a través de la creación } \\
\text { de experiencias sensoriales en ausencia de estímulos externos, } \\
\text { involucrando los sentidos (visuales, auditivas, olfatorias, y cinestésicas) } \\
\text { - Desviar intencionalmente el foco de atención del estímulo ansiógeno a } \\
\text { la relajación }\end{array}$ \\
\hline $\begin{array}{l}\text { Elementos a } \\
\text { considerar }\end{array}$ & $\begin{array}{l}\text { - Puede utilizarse como parte del entrenamiento para el control de } \\
\text { estrés } \\
\text { Esta técnica coadyuva para reducir ansiedad, estrés y dolor; } \\
\text { disminuye la tensión arterial, la frecuencia respiratoria e incrementa } \\
\text { la temperatura periférica, como consecuencia de la activación } \\
\text { parasimpática } \\
\text { - La creación de imágenes y experiencias se construye en conjunto con } \\
\text { el paciente }\end{array}$ \\
\hline $\begin{array}{l}\text { Elementos a } \\
\text { considerar para } \\
\text { no aplicar la } \\
\text { técnica }\end{array}$ & $\begin{array}{l}\text { - La imaginación puede contribuir a elevar los niveles de estrés entre los } \\
\text { individuos que experimentan ansiedad, fobias o depresión, por lo que } \\
\text { debe ser utilizada con cautela }\end{array}$ \\
\hline
\end{tabular}

\section{Técnicas de exposición}

Otro tipo de técnicas que se aplican en conjunto con estrategias para favorecer la relajación (respiración, musculares o imaginadas), son las técnicas de exposición, las cuales intentan ayudar a que los pacientes afronten sus miedos (Lahad \& Doron, 2006; Meadows \& Foa, 1999).

La exposición hace referencia a la presentación sistemática, repetida y/o prolongada de estímulos, objetos o situaciones capaces de desencadenar, de manera exacerbada, un conjunto de respuestas cognitivas, emocionales y conductuales. Dichos estímulos o situaciones se evitan debido a la respuesta de ansiedad que provoca (Clark \& Beck, 2012).

La aplicación de esta técnica en el tratamiento de personas con TEPT se deriva de las premisas del modelo bifactorial de Mowrer, en el que se refiere que una respuesta de miedo o ansiedad inicia al asociarse un estímulo neutro (encontrarse en un elevador o en un tercer piso) con un estímulo incondicionado aversivo (temblor). Como resultado, será 
altamente probable que el exponerse a un elevador o un tercer piso genere respuestas ansiógenas o de temor, las cuales se mantendrán a lo largo del tiempo si las situaciones ya mencionadas se evitan. Es decir, la evitación no permite la experiencia de síntomas asociados con la situación y, por ende, se ven reforzados de forma negativa. Por lo tanto, la exposición funciona bajo los procesos de habituación y extinción. Esto es, se favorece un proceso de familiarización con la situación traumática o su valoración, lo que implica una reducción paulatina en las formas de respuestas exacerbadas a través del tiempo y, posteriormente, con un debilitamiento de las respuestas condicionadas (emocionales y cognitivas) por la eliminación del refuerzo (Antony \& Barlow, 2006; Clark \& Beck, 2012; Norrholm \& Jovanoic, 2010; Pieschacón, 2011).

Generalmente, las técnicas de exposición son la primera línea en el tratamiento de diversos trastornos de ansiedad, además de contar con un importante soporte empírico; su propósito es favorecer la regulación de las respuestas de ansiedad y miedo, afrontar funcionalmente las situaciones traumáticas y limitar la evitación de las situaciones ansiógenas. El tratamiento incluye una jerarquización de situaciones que generan ansiedad, las cuales se van enfrentando de manera gradual (Norrholm \& Jovanoic, 2010; Zayfert \& Black-Becker, 2008).

Se han identificado una serie de pasos que facilitan la implementación de la técnica en pacientes con TEPT, los que se describen a continuación son sólo alguno de ellos (Norrholm \& Jovanoic, 2010; Zayfert \& Black-Becker, 2008):

1. Análisis y explicación de la base lógica que justifique la exposición: en esta etapa se psicoeduca sobre la técnica de exposición y la lógica para aplicarla, además de apoyar al paciente a identificar las situaciones generadoras de ansiedad y la relación entre la situación, su conducta, evaluación y respuestas emocionales.

2. Desarrollo de la jerarquización de situaciones ansiógenas: en esta etapa se enlistan las situaciones que generan ansiedad con base en una valoración de ansiedad provocada.

3. Construcción de un plan para enfrentar funcionalmente las situaciones ansiógenas: en esta etapa se proponen las pautas y condiciones bajo las cuales el paciente se expondrá sistemáticamente con las situaciones temidas. Es necesario contar con un plan que evite que el paciente desista de exponerse y de permitirse a sí mismo experimentar las sensaciones de ansiedad y su proceso a lo largo de las sesiones. 
4. Planear la práctica en la vida cotidiana del paciente: en esta etapa se plantean los ejercicios en vivo y en las situaciones reales donde vive el paciente. Es necesario mencionar que, para esta etapa, el paciente ya cuenta con varias sesiones de entrenamiento.

Los puntos antes mencionados se pueden llevar a cabo por medio de tres procedimientos: a) exposición imaginaria (o también llamada en imaginación): en la que los pacientes son guiados para imaginarse a sí mismos enfrentándose a las situaciones que les produce malestar (recomendada cuando las situaciones ansiógenas no se pueden reproducir o las respuestas de ansiedad son favorecidas por el recuerdo del evento); b) exposición in vivo: en este procedimiento el paciente enfrenta la situación de manera real durante la sesión terapéutica o como actividad fuera del contexto terapéutico; y c) exposición interoceptiva: en ella se pone en práctica el afrontamiento a los síntomas fisiológicos (Báguena, 2013; Lahad \& Doron, 2010; Norrholm \& Jovanoic, 2010; Meadows \& Foa, 1999). Dentro de estos procedimientos se puede incluir a la desensibilización sistemática, debido a que se le considera precursora de las técnicas de exposición (Báguena, 2013).

La desensibilización sistemática hace referencia a una combinación entre exposición y relajación; el proceso implica una exposición gradual a las situaciones traumáticas o evitadas (recuerdos, imágenes o lugares), combinándola con relajación, esto con el objetivo de inhibir las manifestaciones de ansiedad (derivadas de la exposición) al aplicar la relajación. La desensibilización sistemática encuentra su base teórica en los principios del condicionamiento clásico, ya que la respuesta condicional de ansiedad puede ser modificada, reducida o eliminada a través del establecimiento de una respuesta incompatible a ésta, como lo es la relajación. Wolpe (1958) señala que este procedimiento se denomina inhibición recíproca, concepto tomado de Sherrington (1932) quien refiere -en fisiología- que la respuesta de contracción de un músculo debía acompañarse de la inhibición recíproca del antagonista. Utilizando esta lógica, Wolpe asume que ansiedad y relajación funcionan como antagonistas. Entonces, inhibición recíproca, antagonismo y homeostasis ofrecen el fundamento teórico del trabajo de desensibilización de Wolpe y el procedimiento, en términos operacionales, supone un contracondicionamiento, es decir, el condicionamiento del estímulo ansiógeno a la respuesta incompatible (Reynoso, s.f.; Wolpe \& Lazarus, 1966). Cabe señalar que dicha exposición, al ser gradual, requiere de 
una clasificación de situaciones traumáticas, es decir, una lista en la que se determine las situaciones que generan malestar, así como su grado de malestar, y de esta forma se determinarán las situaciones que encabezarán el entrenamiento (normalmente de las que generan menos malestar hacia las que generan mayor malestar).

Los pasos en el proceso de desensibilización sistemática son los siguientes (Meadows y Foa, 1999):

1. El paciente debe ser entrenado en relajación muscular progresiva, para así desarrollar la habilidad de relajarse.

2. Estando en sesión y cuando el paciente se encuentre relajado, se introducen de manera imaginaria las descripciones de las situaciones ansiógenas, esto dará como resultado que el paciente se empiece a sentir ansioso; una vez que llegue a este punto, se le instruirá para que intente controlar las respuestas de ansiedad por medio de la práctica de relajación.

3. Este proceso de relajación-ansiedad-control por relajación se seguirá repitiendo hasta que las propiedades ansiógenas de la descripción del evento se debiliten.

4. Posteriormente, se continúa con la situación que genere un mayor malestar y así sucesivamente hasta que se cumpla con la lista total de situaciones traumáticas, sin que éstas generen un nivel de ansiedad no manejable.

Finalmente, a pesar de que la exposición, en sus diferentes modalidades, son de las técnicas de intervención más importantes en el tratamiento del TEPT, Meadows \& Foa (1999) y Lahad \& Doron (2010) proponen una serie de recomendaciones para tener éxito en la aplicación de estas técnicas:

1. Desarrollar una buena relación terapéutica con el paciente.

2. Clarificación del por qué se tienen que narrar o describir nuevamente los eventos traumáticos.

3. Regular las expectativas de lo que se puede alcanzar con la técnica, sin dejar de lado la nueva exacerbación de los síntomas.

4. Tener el control sobre el tiempo de exposición y el nivel de amenaza.

5. Guía para que el paciente se centre en el aspecto emocional durante la práctica de exposición.

6. Apoyo para disminuir las conductas de evitación. 
Otras consideraciones para su aplicación se encuentran en la Tabla 3.4.

\section{Tabla 3.4. Desensibilización sistemática: consideraciones para su aplicación}

\begin{tabular}{lll} 
& \multicolumn{1}{c}{ Desensibilización sistemática } \\
Objetivo & $\begin{array}{l}\text { Que el paciente reduzca el malestar emocional a través de la } \\
\text { exposición controlada, sistemática, jerarquizada, repetida y/o } \\
\text { prolongada de estímulos asociados a un evento traumático, previa } \\
\text { relajación }\end{array}$ \\
\hline $\begin{array}{l}\text { Elementos a } \\
\text { considerar }\end{array}$ & $\begin{array}{l}\text { Construir una jerarquía de estímulos ansiógenos y ordenarlos de } \\
\text { aquellos que provocan menor a mayor ansiedad }\end{array}$ \\
$\begin{array}{l}\text { Elementos a } \\
\text { considerar para } \\
\text { no aplicar la } \\
\text { técnica }\end{array}$ & $\begin{array}{l}\text { Contar con habilidades de relajación a la par de que se entrena en } \\
\text { exposición }\end{array}$ \\
\hline
\end{tabular}

\section{Entrenamiento en inoculación de estrés}

Esta técnica tiene como propósito favorecer el automonitoreo y la práctica de conductas de afrontamiento funcionales al enfrentar situaciones que generan estrés. En el contexto del TEPT, este entrenamiento se utiliza con frecuencia para el manejo de situaciones aplicadas a la ansiedad, ya que se parte del supuesto que ésta, cuando se presenta en forma excesiva, es derivada del déficit de diferentes habilidades. Es una de las técnicas que más se aplican en el tratamiento del TEPT, fue desarrollada por Meichenbaum en 1974 y posteriormente adaptada para diferentes situaciones asociadas al TEPT (Báguena, 2013; Lahad \& Doron, 2010; Meadows \& Foa, 1999; Pieschacón, 2011).

De manera general, los componentes que incluye esta técnica son: 1) psicoeducación (trauma, reacciones emocionales, fisiológicas y conductuales); 2) desarrollo de habilidades de afrontamiento funcionales; y 3) puesta en práctica de las habilidades aprendidas. Las principales habilidades que se intenta desarrollar y posteriormente poner en práctica son: relajación, respiración diafragmática, juego de roles, ensayos conductuales en vivo e imaginados e imaginación guiada, detención del pensamiento y autoinstrucciones (Báguena, 2013; Lahad \& Doron, 2010; Meadows \& Foa, 1999; Pieschacón, 2011). 
El entrenamiento de inoculación de estrés (EIE) se enfoca en ayudar a los pacientes a comprender y controlar sus reacciones relacionadas al trauma y el protocolo está constituido por tres fases, como se observa en la Tabla 3.5.

\section{Tabla 3.5. Fases del entrenamiento en inoculación de estrés}

\section{Fase: Educativa}

- Presentación del tratamiento

- Información sobre el tipo de respuestas relacionadas al trauma (basadas en la teoría del aprendizaje) a nivel cognitivo, emocional, conductual y fisiológico

- Información relacionada al funcionamiento del sistema nervioso simpático

- Entrenamiento informativo en técnicas de relajación

\section{Fase: Habilidades de afrontamiento}

- El objetivo de esta fase es enseñar al paciente a controlar las respuestas de temor asociadas al trauma en los diferentes niveles de respuesta. Durante esta fase se incluyen técnicas como:

- Respiración diafragmática

- Detención del pensamiento

- Ensayo encubierto

- Autoinstrucciones

- Role Playing

- Solución de problemas

\section{Fase: Aplicación de las habilidades de afrontamiento}

\section{en situaciones de vida cotidiana}

- El objetivo de esta fase es aplicar paso a paso cada una de las estrategias de afrontamiento en situaciones cotidianas

- Esta fase incluye evaluaciones de situaciones estresantes relacionadas o no relacionadas al evento traumático, controlar los comportamientos de evitación, controlar la crítica a uno mismo, así como los pensamientos de carácter rumiativo y autoreforzar positivamente la ejecución exitosa ante el enfrentamiento con estresores

En lo que respecta a los principales componentes de intervención, en la parte psicoeducativa se pretende cubrir tres aspectos fundamentales (Báguena, 2013; Lahad \& Doron, 2010; Meadows \& Foa, 1999; Pieschacón, 2011):

1. Educación sobre la asociación entre eventos traumáticos y el desarrollo de respuestas psicológicas (cognitivas, emocionales y conductuales) ante el trauma. 
2. Educación sobre cómo las respuestas psicológicas se generalizan a otros estímulos o propiedades similares de las situaciones traumáticas, y

3. Educación del papel de las conductas de evitación ante situaciones traumáticas o generalizadas.

Por su parte, con relación a las habilidades de afrontamiento:

1. Las habilidades de respiración y relajación van dirigidas al manejo y la reducción de las manifestaciones fisiológicas y emocionales del TEPT.

2. El juego de roles y la imaginación guiada tienen como propósito abordar el componente conductual del TEPT, en particular, poner en práctica conductas para afrontar las situaciones traumáticas (exposición, modelado, entre otras).

3. La detención de pensamientos y las autoinstrucciones van orientadas a los aspectos cognitivos del TEPT, es decir, a favorecer una regulación y orientación funcional de los pensamientos asociados a las situaciones traumáticas (apoyados con conductas y señales que impidan que un pensamiento perturbador repercuta emocional y conductualmente, y estructurando una serie de pasos e instrucciones para cumplir un objetivo funcional de afrontamiento).

Algunas consideraciones que el psicólogo debe tener en cuenta durante la implementación de esta técnica se observan en la Tabla 3.6.

\section{Tabla 3.6. Entrenamiento en inoculación de estrés: consideraciones para su aplicación}

\section{Entrenamiento en inoculación de estrés}

- Que el paciente modifique la valoración que tiene acerca de la situación estresante y los recursos de que dispone para afrontarla de forma efectiva

- Modificar el comportamiento del paciente mediante la adquisición de

Objetivo estrategias y habilidades

- Propiciar una actividad autorreguladora respecto a imágenes, autoverbalizaciones, pensamientos y sentimientos, con el objetivo de reducir la frecuencia y/o impacto de dichas cogniciones

- Modificar la valoración que el individuo tiene de la situación y de su capacidad para afrontarla 


\section{Entrenamiento en inoculación de estrés}

- Realizar un análisis cuidadoso de lo que se tiene que entrenar

- Ser flexible como terapeuta para construir el entrenamiento de

Elementos a considerar acuerdo a las situaciones específicas del paciente y sus capacidades

- Primero, debe conceptualizar el problema, para que posteriormente el paciente, ayudado por el terapeuta, adquiera habilidades que le sirvan para enfrentar el estrés, que las ensaye y reciba retroalimentación, para finalmente aplicar en el escenario real

- Falta de recursos cognitivos por parte del paciente, es decir:

Elementos a considerar para no aplicar la técnica

* Que no sea capaz de identificar y diferenciar entre pensamientos y sentimientos

* Que no sea capaz de generar autoinstrucciones

- El número de sesiones

\section{Autoinstrucciones}

Dada la naturaleza de los pensamientos y las emociones que acompañan el TEPT se deben emplear técnicas que permitan un adecuado control de ellas a partir del diálogo autodirigido. La idea del uso de estas técnicas radica en enseñar al paciente a anticipar las consecuencias derivadas de los recuerdos del evento traumático y emplear sus recursos disponibles para lograr su ajuste al contexto, siendo las autoverbalizaciones un medio para regular el sentir y el actuar.

La técnica de autoinstrucciones implica que se pueden iniciar o inhibir conductas voluntariamente bajo el control verbal. Ejemplos de este control verbal se ofrecen en tres diferentes niveles: 1) Cuando el terapeuta dirige la conducta de un paciente por medio de verbalizaciones específicas; 2) Ese control es extendido al paciente y éste, por medio de verbalizaciones, es capaz de regular su propio comportamiento; y 3) Se da cuando el mismo paciente es capaz de regular su comportamiento, pero por medio de un diálogo encubierto (Meichenbaum, 1977).

Meichenbaum (1987) menciona que las autoinstrucciones fomentan una actitud activa ante la resolución de problemas. El autodiálogo está pensado para ayudar a los pacientes a evaluar las exigencias derivadas del evento, planificar alternativas de solución para el resguardo de la vida, controlar los pensamientos recurrentes, calificar y autorrecompensar el actuar, controlar las emociones disfuncionales y reflexionar sobre su actuar, previendo posibles obstáculos y resaltando sus fortalezas. 
En este sentido, las autoinstrucciones deben ser diseñadas por los pacientes con ayuda del terapeuta para que sean congruentes con el contexto de cada uno. Debe quedar claro que las autoinstrucciones no son oraciones que el paciente tendrá que repetir mecánicamente, su función consiste en vincular las demandas ambientales y su comportamiento (pensamientos, emociones y conducta), favoreciendo resultados funcionales y haciendo reflexivo este proceso, identificando el control que tiene sobre el mismo.

En el caso de los pacientes con TEPT, las autoinstrucciones deben ser formuladas para dotar al paciente de habilidades que le permitan regular las respuestas cognitivas, emocionales y conductuales derivadas del evento traumático. La continua evaluación de la función que tienen las frases es esencial a lo largo de todo el entrenamiento, ya que, de ser necesario, se integrarán o eliminarán, considerando los avances del paciente.

Por lo tanto, si se requiere entrenar a un paciente para que regule respuestas cognitivas y emocionales, se puede determinar que el objetivo del proceso autoinstruccional debe ser el estar relajado. Para ello, se debe favorecer el control de la situación (percepción de un evento, sensación o pensamiento manejable); posteriormente, se puede descomponer el problema (identificar si se está en un lugar seguro, qué conductas llevar a cabo para ponerse a salvo, o descomponer la relación entre un evento [alarma], su reacción emocional y conductual); una vez realizado esto se está en mejores condiciones para planear cómo resolver un problema (regular las respuestas fisiológicas por medio del análisis situacional y respiración, derivado de autoinstrucciones y pasos clave); aunque esto puede no garantizar la solución del problema, ya que hay ciertos eventos que no dependen del todo de uno, por ello, se debe orientar a que el paciente sea perseverante a la práctica de solución de problemas. Con estos puntos cubiertos, la habilidad para regularse y estar controlado será menos problemática, y una vez que se pueda identificar el éxito del control voluntario mediante autoinstrucciones, será necesario autorreforzarse (Mendoza, 2010).

\section{Técnicas Cognitivas}

La modificación del comportamiento verbal hace referencia a aquellas estrategias que tienen como propósito modificar y/o disminuir formas de pensamiento no funcionales asociadas a un evento traumático o al significado que se le otorgue a éste. Estas estrategias parten del supuesto de que la forma en la que pensamos o valoramos los eventos, 
más que los eventos en sí, se vinculan directamente con la forma en la que nos sentimos y la forma en la que nos comportamos. Por esta razón, en la medida que se modifique la forma de pensar o valorar, se modificarán las emociones y los comportamientos que llevamos a cabo (Clark \& Beck, 2012).

En el caso de los pacientes con TEPT y particularmente aquellos que presentan alteraciones emocionales y conductuales de importancia, tienden a desarrollar formas de pensamiento disfuncionales y valorarán que la o las amenazas traumáticas continúan presentes, se perciben incapaces de hacer frente a las situaciones negativas o pueden anticipar resultados adversos de los eventos cotidianos; esto los pone en riesgo de atender selectivamente a estímulos aversivos, pensamientos negativos, respuestas fisiológicas, emociones negativas y conductas de evitación, es decir, estas consecuencias están en función de la interpretación que se le dé a una situación o evento traumático (Báguena, 2013; Clark y Beck, 2012; Meadows y Foa, 1999; Nezu et al., 2006; Pieschacón, 2011).

En este sentido, el propósito fundamental de la reestructuración cognitiva es favorecer una revaloración o reinterpretación del o los eventos traumáticos; básicamente, el proceso de restructuración implica ayudar a los pacientes a desarrollar habilidades para identificar pensamientos disfuncionales, valorarlos, modificarlos y reemplazarlos por otros, dicho proceso incluye los siguientes pasos (Bados, 1996; Clark \& Beck, 2012; Meadows \& Foa, 1999; Zayfert \& Black-Becker, 2008):

1. Identificar situaciones que provoquen malestar emocional.

2. Identificar respuestas emocionales particulares provocadas por las situaciones, así como valorar su intensidad (en una escala de 0 a 100 o 0 a 10 puntos).

3. Identificar pensamientos relacionados con las emociones negativas y las situaciones, así como valorar el grado en el cual el paciente cree cada pensamiento.

4. Reunir evidencia a favor y en contra de los pensamientos negativos previamente identificados.

5. Una vez que se cuente con ambas formas de evidencia es necesario hacer una revaloración de los pensamientos identificados y analizados, y

6. Finalmente, se hace una revaloración de las consecuencias emocionales que generan las situaciones traumáticas (Ver Anexo 4). 
Es necesario referir que la técnica de reestructuración cognitiva también se emplea en el manejo de los flashbacks, mismos que se perciben por el paciente como respuestas estresantes aversivas e inalterables. Por ello, es de vital importancia generar estrategias que conlleven compromiso y que permitan alterar su significado. Acciones como stop a las ideas, o la introducción de un estímulo condicionado que, emparejado con la presencia de estos recuerdos, permita la focalización de la atención ante este estímulo novedoso, posibilitando el cese de las respuestas desadaptativas. Otras estrategias que pueden favorecer la reducción de los pensamientos angustiantes asociados al evento traumático es la extinción de fuentes informativas que relatan (a veces distorsionadas) las consecuencias derivadas del evento. Este "ayuno de noticias" permite no sólo el cese de los pensamientos sino también que el organismo se prepare y esté atento a otros estímulos el ambiente.

En la Tabla 3.7. se pueden observar algunas consideraciones en la aplicación de las técnicas de modificación de pensamientos.

\section{Tabla 3.7. Técnicas cognitivas: consideraciones para su aplicación}

\begin{tabular}{lll} 
& \multicolumn{1}{c}{ Técnicas Cognitivas } \\
Objetivo & $\begin{array}{l}\text { Identificar pensamientos o verbalizaciones disfuncionales (irracionales } \\
\text { o no) que generan malestar o conductas no adaptativas y sustituirlos } \\
\text { por otros funcionales }\end{array}$ \\
\hline & - Identificar los pensamientos disfuncionales \\
& Discutir el impacto de los pensamientos sobre las reacciones \\
Elementos a & emocionales y sobre el comportamiento del paciente \\
considerar & Considerar los pensamientos como hipótesis que deben ser discutidas \\
& y sometidas a prueba
\end{tabular}


Aunque en este capítulo se exploraron sólo algunas de las estrategias con enfoque cognitivo-conductual para el tratamiento del TEPT, debe quedar claro que el entrenamiento no debe incluirlas todas; por el contrario, éstas deben ser ajustadas y utilizadas según las características y evolución del paciente. El uso de estas técnicas ha resultado eficaz para el tratamiento individual de este trastorno (Bisson, Roberts, Andrew, Cooper \& Lewis, 2013). 


\section{Capítulo 4}

\section{Características del terapeuta que atiende al paciente con TEPT}

El tratamiento psicológico para el TEPT o cualquier tipo de trastorno incluye la puesta en marcha de estrategias terapéuticas que requieren habilidades por parte del profesional que lo ejerce. Por tanto, se requiere de ciertas características, conocimiento de ciertos temas y habilidades prácticas para su intervención para lograr un efecto terapéutico clínico exitoso. Es necesario entonces que el psicólogo esté debidamente capacitado y, desde la opinión de los autores de esta obra, que cuenten con los estudios y certificaciones profesionales, ya que los fracasos en la mitigación, preparación y respuesta ante un evento traumático se deben, en gran medida, a la falta de capacitación específica y relacionada con los trastornos que ocasiona un evento traumático, así como a la deficiente coordinación entre los distintos profesionales. Para ello, se requiere entonces de formación académica y entrenamiento, así como educación continua y actualización (Lo Coco, Gullo, Prestano \& Gelso, 2011; Organización Panamericana de la Salud [OPS], 2000).

Con relación a las características que debe poseer el profesional de la Psicología que atienda a un individuo con TEPT, debemos colocar como obligatorias las siguientes:

1. Contar con título profesional expedido por una Universidad.

2. Contar con una cédula profesional que le permita trabajar legalmente.

3. Pertenecer a un colegio de psicólogos.

4. Estar certificado como terapeuta entrenado para atender TEPT. 
Si no se cuenta con estas características, entonces se asume otro tipo de trabajo psicológico: el coadyuvar al tratamiento del TEPT y, para ello, es deseable que se cuente con las siguientes características:

- Estudios. Tener al menos el 50\% de los créditos de la carrera de psicología.

- Edad. De preferencia personas mayores de 21 años que es la edad aproximada en la que se adquiere un nivel de madurez y responsabilidad del cuidado personal.

- Personalidad previa. Específicamente se requiere de capacidad para afrontar situaciones de dolor y gravedad, calidez y empatía, así como capacidad de contención y autocontrol.

- Capacidad para trabajar en equipo. Evitar protagonismos y reconocer las limitaciones personales.

- Experiencia previa en el contexto de la práctica clínica. Se requiere que el profesional tenga práctica clínica y experiencia en la atención de pacientes.

- Motivación y disposición para ayudar a otros. Conocer los requerimientos de su actuación y desarrollar sus actividades considerando la urgencia de las situaciones sociales e individuales.

- Formación. Aumentar la eficacia de las diferentes actuaciones disciplinarias, adquirir habilidades sociales básicas y de comunicación, diseñar e implementar estrategias bajo un modelo teórico consolidado y metodologías basadas en evidencia.

- Conocer e identificar las diferentes manifestaciones del estrés postraumático tanto en víctimas como en sí mismo. Conocimiento respecto a los criterios diagnósticos del TEA y del TEPT, además de conocer los diferenciales diagnósticos y comorbilidades asociadas a este tipo de trastornos. (Dutch, Fortuño \& Lacambra, citados en San Juan, 2001)

Los conocimientos, habilidades, destrezas y competencias con los que debe contar el psicólogo que proporciona apoyo son: habilidad en el control de respuestas emocionales (intervención en crisis y primeros auxilios psicológicos), conocimientos de cómo se evalúan, diseñan e implementan los planes de intervención clínica para los pacientes que experimentaron un trauma, conocimiento de los criterios diagnósticos para concluir qué tipo de trastorno tiene el paciente (uso de los manuales diagnósticos estandarizados DSM y la Clasificación Internacional de Enfermedades [CIE]), dominio de métodos para la 
evaluación del cambio clínico (inventarios, escalas, autorregistros), así como de modelos de análisis de la conducta técnicas de intervención eficaces en pacientes con TEPT. Contar con este tipo de elementos permitirá al terapeuta tener control de las reacciones o complicaciones que se presenten a lo largo del proceso terapéutico, pero también le permitirá modificar e incluso predecir las respuestas asociadas al trastorno (Gavino, 2006; Reyes \& Tena, 2016).

\section{Actividades a realizar por el terapeuta ante el TEPT}

Para Reyes y Tena (2016), Bohart y Greenberg (1997) o San Juan (2001) es elemental que el terapeuta inspire confianza al paciente y, así, favorezca la verbalización de sentimientos en el contexto de la terapia y la permanencia en la misma. Para lograrlo debe poner en marcha una serie de actividades y poseer una serie de actitudes y valores como:

- Escuchar de forma activa y atenta al paciente. Esta actividad permitirá al terapeuta identificar todos aquellos detalles relacionados al trauma y sus efectos psicosociales en el paciente. Es necesario dejar hablar al paciente sin interrumpir el discurso, salvo que sea necesario (por ejemplo: que el paciente pierda el hilo conductor de la conversación o divague en detalles innecesarios). El terapeuta podría colaborar con él para obtener información, proporcionando ejemplos, realizando preguntas con el propósito de evitar la dispersión de las respuestas, pero nunca deberá sugerir la respuesta.

- Observar al paciente. Tomar en cuenta el lenguaje no verbal de paciente (gestos, ademanes, movimientos) y su apariencia (luce cansado, con adecuado aliño e higiene, etc.).

- Indagar sobre las creencias relacionadas al evento traumático. Las ideas relacionadas a la presencia del evento traumático contribuyen en gran medida a la percepción de gravedad o novedad que tiene el paciente y puede facilitar o entorpecer la adaptación (por ejemplo: en algunas comunidades los desastres naturales son interpretados como una manifestación de la madre tierra o incluso como una advertencia de las deidades).

- Mostrar empatía y respeto por las emociones manifestadas por el paciente. Cuando el paciente se sabe escuchado y comprendido se genera un espacio de confianza y tranquilidad que posibilita la expresión de emociones. 
- Responder ante las crisis emocionales o flashbacks. Estar entrenado para realizar contención emocional y administrar atención psicológica in situ (si se considera necesario) y a corto plazo.

- Informarse y diseñar mecanismos de información para el paciente o la población en general. Tener acceso a datos confiables ayuda a mitigar las creencias inadecuadas del evento traumático. Permite también la búsqueda y solicitud de apoyo (instituciones, centros de canalización para la atención multidisciplinaria) y tener conocimientos de los trastornos psicológicos secundarios al evento traumático.

- Capacidad de emitir mensajes con claridad. Verificar si el paciente ha comprendido realmente aquello que se dice, particularmente si se encuentra en riesgo o carece de apoyo de otros si se presenta una emergencia.

- Capacidad de generar un diagnóstico psicológico e identificación de comorbilidades. Verificar si el comportamiento obedece al TEPT o a alguna otra circunstancia o condición (por ejemplo: problemas de origen biológico, síntomas de otro trastorno o efectos secundarios del tratamiento médico).

- Identificar el tipo de apoyo que se necesita y en qué momento. Se trata de sumar y no de entorpecer la movilización del apoyo.

- Habilidad para diseñar e implementar programas de intervención ajustadas a las características individuales.

- Dominio de técnicas y procedimientos metodológicos para este tipo de casos. Técnicas eficaces y basadas en la evidencia.

- Entrenar al paciente en técnicas que permitan la recuperación de su vida cotidiana. Posterior al evento traumático, facilitar el aprendizaje de hábitos cotidianos y saludables.

- Ser directivo. Proporcionar instrucciones claras y precisas e indicar al paciente el curso que puede tomar el proceso terapéutico o incluso los cambios que se esperan contribuyen a la reducción del impacto psicológico y evitar la cronificación de los síntomas asociados al trastorno.

- Diseñar mecanismos de información para la población. Ofrecer información y educación útil y confiable que ayude a mitigar las creencias inadecuadas del evento traumático y que ofrezca alternativas de ajuste a las directrices para el control de contingencias y para la solicitud de apoyo (instituciones, zonas de apoyo, centros 
de canalización para la atención multidisciplinaria) y de los trastornos psicológicos secundarios al evento traumático.

- Facilitar el aprendizaje de hábitos saludables y de control de riesgo sanitario posterior al evento traumático.

- Capacitar y entrenar a los cuerpos de primera intervención (policías, bomberos, cuerpos de rescate, profesionales de salud) en la autorregulación emocional, la intervención ante las crisis y estrategias para la prevención de psicopatologías secundarias (TEPT, ansiedad, depresión y síndrome de burnout).

- Capacidad de reconocer sus habilidades y limitaciones. Que el terapeuta descubra las emociones que se derivan de la atención de un paciente (independientemente del trastorno que éste tenga) permitirá el ejercicio profesional y ético, pero además evitará un daño al paciente.

En el caso del terapeuta se hace necesaria la capacitación para desarrollar competencias, no sólo para superar el desastre sino ayudar a los pacientes a afrontar las secuelas del mismo, por ejemplo: la pérdida material, las grandes concentraciones humanas que se hacinan en las calles viviendo en casas de campaña sin infraestructura, sin recursos y sin apoyo.

Es fundamental que el terapeuta tenga un buen control de los estados de crisis y activación fisiológica intensa ya que incluso son indicadores de severidad del trastorno. Desde el modelo conductual este tipo de alteraciones son consideradas como respuestas de evitación (supresión de los pensamientos e imágenes intensas) que con el paso del tiempo por la asociación con situaciones relacionadas resultan en el aprendizaje de las respuestas y, por tanto, se presentan de forma automática (Vargas \& Coria, 2017). Para estos autores, el protocolo para el control de la crisis en los pacientes con TEPT incluye: identificación de la emoción predominante y del evento/situación que la provoca, identificar las condiciones en las que ocurre el problema y proporcionar refuerzo positivo verbal ante la solicitud de ayuda, evaluar la intensidad del malestar que provoca la imagen o recuerdo (por ejemplo, se puede utilizar una escala subjetiva análoga con calificación del 0 al 10), identificar las respuestas fisiológicas derivadas, ayudar al paciente a que identifique elementos de la situación que se vive en el aquí y el ahora o un evento neutral alejado de las imágenes derivadas del evento traumático, programar actividades incompatibles 
a todas aquellas que resultan en la presencia de recuerdos disfuncionales. Consideramos que otras estrategias que permitirán la atención oportuna de los pacientes con TEPT, no sólo incluye la capacitación de los profesionales de la salud sino también la creación de una base de datos de profesionales especialistas organizados por áreas de experiencia en la intervención del estrés postraumático, la implementación de un sistema de coordinación sanitaria ante las emergencias y, por supuesto, un protocolo de actuación ante los eventos de alto impacto relacionados a la evaluación de los daños a nivel material y psicológico. 


\section{Referencias}

American Psychiatric Association (APA). (2006). Guía clínica para el tratamiento de los trastornos por estrés agudo y estrés postraumático. España: Ars Médic.

American Psychiatric Association (APA). (2013). Diagnostic and Statistical Manual of Mental Disorders (DSM-5). Washington, D.C: The American Psychiatric Association.

American Psychological Association (APA). (2017). Clinical practice guideline for the treatment of PTSD. Recuperado de http://www.apa.org/ptsd-guideline/ptsd.pdf

Antony, M.M., \& Barlow, D.H. (2006). Fobia específica. En V. Caballo (Comp.), Manual para el tratamiento cognitivo-conductual de los trastornos psicológicos: Trastornos por ansiedad sexual, afectivos y psicóticos (pp. 3-24). España: Siglo XXI.

Astin, M., \& Resick, P. (2006). Tratamiento Cognitivo Conductual del Trastorno por estrés postraumático. En. V. Caballo (Dir.), Manual para el tratamiento cognitivo conductual de los trastornos psicológicos. Vol I.Trastornos por ansiedad, sexuales, afectivos y psicóticos (pp. 171-209). España: Siglo XX1.

Bados, A. (1996). La técnica de la reestructuración cognitiva. En J.M. Alberca y C. Prieto (Comps.), Manual práctico de psicología clínica y de la salud (pp. 15-48). Málaga: Publicaciones del Centro Clínico Los Naranjos. 
Báguena, M.J. (2013). Guía de tratamientos psicológicos eficaces para el trastorno de estrés postraumático. En M. Pérez, J. Fernández, C. Fernández e I. Amigo (Coords.), Guía de tratamientos psicológicos eficaces I: Adultos (pp. 311-335). Madrid: Pirámide.

Baker, C.K., Norris, F.H., Jones, E.C., \& Murphy, A. D. (2009). Childhood trauma and adulthood physical health in Mexico. Journal of Behavioral Medicine, 32(3), 255269. http://doi.org/10.1007/s10865-009-9199-2

Barret, K.E, Boitano, S., Barman, S.M., \& Brooks, H.L. (2010). Ganong's review of medical physiology. New York: McGraw Hill.

Başoglu, M., Kiliç, C., Şalcioglu, E. \& Livanou, M. (2004). Prevalence of posttraumatic stress disorder and comorbid depression in earthquake survivors in Turkey: An epidemiological study. Journal of Traumatic Stress, 17(2), 133-141. http://doi. org/10.1023/B:JOTS.0000022619.31615.e8

Bäuml, J., Froböse, T., Kraemer, S., Rentrop, M., \& Pitschel-Walz, G. (2006). Psychoeducation: a basic psychotherapeutic intervention for patients with schizophrenia and their families. Schizophrenia Bulletin, 32 (Suppl 1), S1-S9

Becerra, A.L., \& Reynoso, L. (2014). Efectos del comportamiento terapéutico e interacción con el paciente. En L. Reynoso y A.L. Becerra (Coords.), Medicina Conductual: teoría y práctica. Hermosillo: Qartuppi. http://doi.org/10.29410/QTP.14.01

Beck, B.D., Messel, C., Meyer, S.L., Cordtz, T.O., Søgaard, U., Simonsen, E., \& Moe, T. (2018). Feasibility of trauma-focused Guided Imagery and Music with adult refugees diagnosed with PTSD: A pilot study. Nordic Journal of Music Therapy, 27(1), 67-86. http://doi.org/10.1080/08098131.2017.1286368

Bennett, P. (2004). Psychological interventions in patients with chronic illness. En A.A., Kaptein, \& J. Weinman (Eds.), Health Psychology (pp. 336-357). Oxford: BPS Blackwell.

Bernstein, D.A., Borkoveck, T.D., \& Hazlett-Stevens, H. (2000). New directions in progressive relaxation training: a guidebook for helping professionals. Westport, CT: Praeger Publishers.

Bisson, J., Roberts, N., Andrew, M., Cooper, R. \& Lewis, C. (2013). Psychological therapies for chronic post-traumatic stress disorder (PTSD) in adults. Cochrane Database of Systematic Reviews, 12. http://doi.org/10.1002/14651858.CD003388.pub4 
Bohart, A., \& Greenberg, L. (Eds.). (1997). Emphaty reconsidered: new directions in psychotherapy. Washington: American Psychiatric Association.

Bolton, E.E., Lambert, J.F., Wolf, E.J., Raja, S., Varra, A.A., \& Fisher, L.M. (2004). Evaluating a Cognitive-Behavioral Group Treatment Program for Veterans with Posttraumatic Stress Disorder. Psychological Services, 1(2), 140-146. http://doi.org/10.1037/15411559.1.2.140

Bridges, P.K., \& Jones, M.T. (1967). Personality, physique and the adrenocortical response to a psychological stress. British Journal of Psychiatry, 113(499), 601-605. http:// doi.org/10.1192/bjp.113.499.601

Cannon, W. (1932). The wisdom of the body. New York: Norton.

Carr, E.G. (1994). Emerging themes in the functional analysis of problem behavior. Journal of Applied Behavior Analysis, 27(2), 393-399. http://doi.org/10.1901/jaba.1994.27393

Chan, C. L. W., Wang, C.-W., Qu, Z., Lu, B. Q., Ran, M.-S., Ho, A. H. Y., Yuan, Y., Zhang, B.Q. Wang, X. \& Zhang, X. (2011). Posttraumatic stress disorder symptoms among adult survivors of the 2008 Sichuan earthquake in China. Journal of Traumatic Stress, 24(3), 295-302. http://doi.org/10.1002/jts.20645

Clark, D.A., \& Beck, A.T. (2012). The anxiety and worry workbook: The cognitive behavioral solutions. New York: The Guilford Press.

Cohen, F., \& Lazarus, R.S. (1973). Active coping processes, coping dispositions, and recovery from surgery. Psychosomatic Medicine, 35-5, 375-389.

Cooper, K., \& Stollings, S. (2010). Guided imagery for anxiety. Journal of Palliative Medicine, 10, 606-607. http://doi.org/10.1089/jpm.2010.9834

Crespo, M., \& Gómez, M.M. (2003). Propuesta de un inventario para la evaluación y diagnóstico de estrés post traumático. Psicopatología Clínica, Legal y Forense, 3(3), 41-57.

Dedert, E.A., Calhoun, P.S., Watkins, L.L., Sherwood, A., \& Beckham, J.C. (2010). Posttraumatic Stress Disorder, Cardiovascular, and Metabolic Disease: A Review of the Evidence. Annals of Behavioral Medicine, 39(1), 61-78. http://doi.org/10.1007/ s12160-010-9165-9 
De la Rosa, A., \& Cárdenas, G. (2012). Trastorno por estrés postraumático: eficacia de un programa de tratamiento mediante realidad virtual para víctimas de violencia criminal en población mexicana. Anuario de psicología, 42(3), 377-391.

Dobson, D., \& Dobson, K. (2009). Evidence-Based Practice of Cognitive-Behavioral Therapy. New York: The Guildford Press.

Durkin, M.E. (1993). Major depression and posttraumatic stress disorder following the Coalinga and Chile earthquakes: A cross-cultural comparison. Journal of Social Behavior and Personality, 8(5), 405- 420.

Echterling, L.G., Field, T., \& Stewart, A. (2015). Evolution of PTSD diagnosis in the DSM. En: M. Safir, H. Wallach \& A. Rizzo (Eds.), Future directions in Post-Traumatic Stress Disorder. Prevention, diagnosis, and treatment (pp. 189-212). Nueva York: Springer. http://doi.org/10.1007/978-1-4899-7522-5

Epstein, G., Halper, J., Manhart, E., Birdsal, C., McGee, M., Baron, K., \& Lowenstein, S. (2004). A pilot study of mind-body changes in adults with asthma who practice mental imagery. Alternative Therapies, 10(4), 66-70.

Flett, R.A., Kanzantzis, N., Long, N.R., MacDonald, C., \& Millar, M. (2002). Traumatic events and physical health in a New Zealand community sample. Journal of Traumatic Stress, 15(4), 303-312. http://doi.org/10.1023/A:1016251828407

Foa, E.B., Steketee, G., \& Grayson, J. B. (1985). Imaginal and in vivo exposure: A comparison with obsessive-compulsive checkers. Behavior Therapy, 16(3), 292-302. http://doi. org/10.1016/S0005-7894(85)80017-4

Foa, E.B. \& Kozak, M.J. (1986). Emotional processing of fear: Exposure to corrective information. Psychological Bulletin, 99(1), 20-35.

Forteza, S., \& Vara, M. (2000). Dos formas de presentar los resultados del análisis funcional de las conductas problema. Psicothema, 12(2), 260-266.

Friedman, M.J. \& Schnurr, P.P. (1995). The relationship between trauma, PTSD, and physical health. En M.J. Friedman, D.S. Charney, \& A.Y. Deutch (Eds.), Neurobiological and clinical consequences of stress: From normal adaptation to PTSD (pp. 507-527). New York: Raven.

Galea, S., Nandi, A., \& Vlahov, D. (2005). The epidemiology of post- traumatic stress disorder after disaster. Epidemiologic Reviews, 27, 78-91. http://doi.org/10.1093/ epirev/mxi003 
Galindo, E. (2010). Intervención de psicólogos de la UNAM Iztacala después de los sismos de 1985 en México. México: AMEPSI Editorial.

Gavino, A. (2006). Guía de técnicas de terapia de conducta. México: Pirámide.

Goenjian, A.K., Najarian, L.M., Pynoos, R.S., Steinberg A.M., Manoukian, G., \& Tavosian, A. (1994). Posttraumatic stress disorder in elderly and younger adults after the 1988 earthquake in Armenia. American Journal of Psychiatry, 151(6), 895-901.

Goenjian, A.K., Steinberg, A.M., Najarian, L.M., Fairbanks, L. A., Tashjian, M., \& Pynoos, R.S. (2000). Prospective study of post-traumatic stress, anxiety, and depressive reactions after earthquake and political violence. American Journal of Psychiatry, 157(6), 911- 916. http://doi.org/10.1176/appi.ajp.157.6.911

Hanley, G.P., Iwata, B.A., \& McCord, B.E. (2003). Functional analysis of problem behavior: a review. Journal of Applied Behavior Analysis, 36(2), 147-185. http://doi.org/10.1901/ jaba.2003.36-147

Haynes, S., \& O'Brien, W. (2003). Principles and practice of behavioral assessment. New York: Kluwer.

Hetrick, S., Purcell, R., Garner, B., \& Parslow, R. (2010). Tratamiento farmacológico y terapia psicológica combinados para el trastorno de estrés postraumático (TEPT). Cochrane Database of Systematic Reviews, 7. http://doi.org/10.1002/14651858. CD007316

Jain, S., McMahon, G. F., Hasen, P., Kozub, M. P., Porter, V., King, R., \& Guarneri, E. M. (2012). Healing touch with guided imagery for PTSD in returning active duty military: A randomized controlled trial. Military medicine, 177(9), 1015-1021. http://doi. org/10.7205/MILMED-D-11-00290

Johnsen, E., \& Lutgendorf, S. (2001). Contributions of imagery ability to stress and relaxation. Annals of Behavioral Medicine, 23(4), 273-281. http://doi.org/10.1207/ S15324796ABM2304_6

Jones, M.T., Bridges, P.K. \& Leak, D. (1970). Correlation between psychic and endocrinological responses to emotional stress. Progress in Brain Research, 32, 325-335. http://doi.org/10.1016/S0079-6123(08)61549-6

Kessler, D. C., Sonnega, A., Bromet, E., Hughes, M., \& Nelson, C. B. (1995). Posttraumatic stress disorder in the National Comorbidity Survey. Archives of General Psychiatry, 52(12), 1048-1060. 
Labrador, F.J., \& Crespo M. (2012). Psicología clínica basada en la evidencia. España: Ediciones Pirámide.

Lancaster, C.L., Teeters, J.B., Gros, D.F., \& Back, S.E. (2016). Posttraumatic Stress Disorder: Overview of evidence-based assessment and treatment. Journal of Clinical Medicine, 5(11), 105. http://doi.org/10.3390/jcm5110105

Lancaster, S.L., Melka, S.E., Rodríguez B.F., \& Bryant, A.R. (2014). PTSD symptom patterns following traumatic and nontraumatic events. Journal of Aggression, Maltreatment \& Trauma, 23(4), 414-429. http://doi.org/10.1080/10926771.2014.893276

Lazarus, R.S. (1999). Stress and emotion. A new synthesis. New York: Springer.

Lazarus, R.S., \& Folkman, S. (1984). Stress, appraisal, and coping. New York: Springer.

Lo Coco, G., Gullo, S., Prestano, C., \& Gelso, C.J. (2011). Relation of the real relationship and the working alliance to the outcome of brief psychotherapy. Psychotherapy, 48(4), 359-367. http://doi.org/10.1037/a0022426

Lohad, M., \& Doron, M. (2010). Protocol for treatment of post-traumatic stress disorder. See for CBT Model: beyond cognitive behavior therapy. England: IOS Press.

Loo, G., DiMaggio, C., Gershon, R., Canton, D., Morse, S., \& Galea, S. (2016). Coping Behavior and Risk of Post-Traumatic Stress Disorder Among Federal Disaster Responders. Disaster Medicine and Public Health Preparedness, 10(1), 108-117. http://doi. org/10.1017/dmp.2015.141

Louie, S. (2004). The effects of guided imagery relaxation in people with COPD. Occupational Therapy International, 11(3), 145-159. https://doi.org/10.1002/oti.203

Marlatt, G.A., \& Donovan, D.M. (Eds.). (2005). Relapse prevention. Maintenance strategies in the treatment of addictive behaviors. New York: The Guilford Press.

Marlatt, G.A., \& George, W.H. (1984). Relapse prevention; Introduction and overview of the model. British Journal of Addiction, 79, 261-273.

McBride, D., Porter, N., Lovelock, K., Shepherd, D., Zubizaretta, M., \& Burch, J. (2018). Risk and protective factors for the course of post-traumatic stress disorder in frontline workers after the Christchurch, New Zealand earthquake. Disaster Prevention and Management: An International Journal, 27(2), 193-206. http://doi.org/10.1108/ DPM-09-2017-0226 
McMillen, J.C., North, C.S., \& Smith, E.M. (2000). What parts of PTSD are normal: Intrusion, avoidance or arousal? Data from the Northridge, California, Earthquake. Journal of Traumatic Stress, 13(1), 57-75. http://doi.org/10.1023/A:1007768830246

Meadows, E., \& Foa, E. (1999). Cognitive behavioral treatment of traumatized adults. En: P. A. Saigh \& D. Bremmer (Eds.), Posttraumatic stress disorder. A comprehensive text (pp. 376-390). London: Library of Congress.

Meda, R.M., Moreno, B., Rodríguez, A., Arias, E.D., \& Palomera, A. (2011). Validación mexicana de la Escala de Estrés Traumático Secundario. Psicología y Salud, 21-1, 5-15.

Medina-Mora, M.E., Borges, G., Fleiz, C., Lara, C., Zambrano-Ruiz, J., \& Ramos, L. (2005) Prevalencia de sucesos violentos y trastorno por estrés postraumático en la población mexicana. Salud Publica de México, 47(1), 8-22.

Meichenbaum, D.H. (1977). Cognitive behavior modification: An integrative approach. New York: Plenum.

Meichenbaum, D. (1987). Manual de inoculación de estrés. Barcelona: Martínez Roca.

Meichenbaum, D. (2017). The evolution of cognitive behavior therapy. New York: Routledge Taylor \& Francis Group.

Mendoza, G.B. (2010). Manual de Autocontrol de Enojo. Tratamiento Cognitivo-Conductual. México: Manual Moderno.

Morrison, J. (2015). La entrevista psicológica. México: Manual Moderno.

Nezu, A.M., Nezu, C.M., \& Lombardo, E. (2006). Formulación de casos y diseño de tratamientos cognitivo-conductuales. Un enfoque basado en problemas. México: Manual Moderno.

Nezu, A.M., \& Nezu, C.M. (2008). Entrenamiento en solución de problemas. En V. Caballo (Comp.), Manual de técnicas de terapia y modificación de conducta (pp. 327-553). España: Siglo XXI.

Norrholm, S., \& Jovanoic, T. (2010). Tailoring therapeutic strategies for treating posttraumatic stress disorder symptom clusters. Neuropsychiatric Disease and Treatment, 6, 517-532. http://doi.org/10.2147/NDT.S10951

Norris, F.H., \& Kaniasty, K. (1994). Psychological distress following criminal victimization in the general population: Cross-sectional, longitudinal, and prospective analyses. Journal of Consulting and Clinical Psychology, 62(1), 111-123. http://doi. org/10.1037/0022-006X.62.1.111 
Organización Panamericana de la Salud (OPS). (2000). Los desastres naturales y la protección de la salud. Washington: Organización Mundial de la Salud. Recuperado de http://apps.who.int/iris/bitstream/10665/167773/1/9275315752.pdf

Organización Panamericana de la Salud (OPS). (2006). Guía Práctica de Salud Mental en Desastres. Washington: Organización Mundial de la Salud.

Outcalt, S. D., Kroenke, K., Krebs, E.E., Chumbler, N.R., Wu, J., Yu, Z., \& Bair, M.J. (2015). Chronic pain and comorbid mental health conditions: independent associations of posttraumatic stress disorder and depression with pain, disability, and quality of life. Journal of Behavioral Medicine, 1-9. http://doi.org/10.1007/s10865-015-9628-3

Overholser, J.C. (1991). The use of guided imagery in psychotherapy: Modules for use with passive relaxation training. Journal of Contemporary Psychotherapy, 21(3), 159-170. https://link.springer.com/article/10.1007\%2FBF00973115

Persons, J.B. (2008). The case formulation approach to cognitive-behavior therapy (Guides to Individualized evidence-based treatment). Nueva York: Guild Press.

Pieschacón, F.M. (2011). Trastorno de estrés postraumático: modelo cognitivo-conductual. Colombia: Uniandes-Universidad de los Andes.

Prakash, J., Saha, A., Das, R., Srivastava, K., \& Shashikuma, R. (2016). Post-traumatic stress disorder. Medical Journal Armed Forces India, 72(2), 189-191. http://doi. org/10.1016/j.mjafi.2015.04.004

Resnick, H.S., Kilpatrick, D.G., Dansky, B.S., Saunders, B.E., \& Best, C.L. (1993). Prevalence of civilian trauma and posttraumatic stress disorder in a representative national sample of women. Journal of Consulting and Clinical Psychology, 61(6), 984-991. http://doi.org/10.1037/0022-006X.61.6.984

Reyes, M., \& Tena, E. (2016). Regulación emocional en la práctica Clínica. Una guía para terapeutas. México: Manual Moderno.

Reynoso, L. (s.f.). Notas sobre estrés fisiológico y ansiedad. Documento no publicado.

Reynoso, L., \& Seligson, I. (2005). Psicología clínica de la salud: Un enfoque conductual. México: Manual Moderno.

Ritz, T., Meuret, A.E., Trueba, A.F., Fritzsche, A., \& von Leupoldt, A. (2013). Psychosocial factors and behavioral medicine interventions in asthma. Journal of Consulting and Clinical Psychology, 81(2), 231-250. http://doi.org/10.1037/a0030187 
Saaren, J. (2014). Posttraumatic stress disorder in adults: impact, comorbidity, risk factors and treatment. Canadian Journal of Psychiatry, 59(9), 460-467.

San Juan, C. (Ed.). (2001). Catástrofes y ayuda de emergencia. Estrategias de evaluación, prevención y tratamiento. Barcelona: Icaria editorial.

Schnurr, P., \& Green, B. (2004). Understanding relationships among trauma, posttraumatic stress disorder, and health outcomes. En P. Schnurr \& B. Green (Eds.), Trauma and health: Physical health consequences of exposure to extreme stress (pp. 247-275). Washington DC: American Psychological Association.

Scotland-Coogan, D., \& Davis, E. (2016). Relaxation techniques for trauma. Journal of Evidence-Informed Social Work, 13(5), 434-441. http://doi.org/10.1080/23761407.2 016.1166845

Secretaría de Salud (SSA). (2011). Guía de Práctica Clínica. Diagnóstico y manejo del estrés postraumático. Recuperado de http://www.cenetec.salud.gob.mx/interior/gpc. html

Selye, H. (1998). A syndrome produced by diverse nocuos agents. 1936. Journal of Neuropsychiatry and Clinical Neurosciences, 10(2), 230-231. http://doi.org/10.1176/ jnp.10.2.230a

Sharan, P., Chaudhary, G., Kavathekar, S.A., \& Saxena, S. (1996). Preliminary report of psychiatric disorders in survivors of a severe earthquake. American Journal of Psychiatry, 153(4), 556-558. http://doi.org/10.1176/ajp.153.4.556

Sherrington, C. (1932). Inhibition as a coordinative factor. Nobel lecture. Recuperado de https://www.nobelprize.org/prizes/medicine/1932/sherrington/lecture/

Sin, J., Spain, D., Furuta, M., Murrells, T., \& Norman, I. (2017). Psychological interventions for post-traumatic stress disorder (PTSD) in people with severe mental illness. Cochrane Database of Systematic Reviews, 1. http://doi.org/10.1002/14651858. CD011464.pub2

Skinner, B.F. (1953). Science and human behavior. New York: The Free Press.

Snyder, C.R. (Ed.). (2001). Coping with stress. Effective people and processes. New York: Oxford University Press.

Tapia, C., Sepúlveda, J., Medina-Mora, M.E., Caraveo, J., \& De la Fuente, J.R. (1987). Prevalencia del síndrome de estrés postraumático en la población sobreviviente a un desastre natural. Salud Pública de México, 29(5), 406-411. 
Tousman, S., Zeitz, H., Taylor, L., \& Bristol, C. (2007). Development, implementation and evaluation of a new adult asthma self-management program. Journal of Community Health Nursing, 24(4), 237-251. http://dx.doi.org/10.1080/07370010701645893

Ullman, S.E., \& Siegel, J.M. (1996). Traumatic events and physical health in a community sample. Journal of Traumatic Stress, 9(4), 703-720. http://dx.doi.org/10.1007/ BF02104098

Universidad Nacional Autónoma de México (UNAM). (2017). Sismos fuertes (del año 2000 a la fecha). Servicio Sismológico Nacional (SSN). Recuperado de http://www2.ssn. unam.mx:8080/sismos-fuertes/

Vargas, A.N., \& Coria, K. (2017). Estrés postraumático. Tratamiento basado en la Terapia de Aceptación y Compromiso (ACT). México: Manual Moderno.

Vázquez, M.I. (2001). Técnicas de relajación y respiración. España: Editorial Síntesis.

Villarreal, M.J. (1981). Fundamentos de entrevista conductual. México: Trillas.

Williams, M.B., \& Poijula, S. (2015). Manual de tratamiento del Trastorno de Estrés Postraumático. Técnicas Sencillas y eficaces para superar los síntomas del TEPT. España: Descleé de Brouwer.

Wolpe, J. (1958). Psychotherapy by reciprocal inhibition. New York: Stanford University Press.

Wolpe, J., \& Lazarus, A. (1966). Behavior Therapy Techniques. Oxford: Pergamon Press. Zayfert, C., \& Black-Becker, C. (2008). Cognitive-Behavioral Therapy for PTSD. A Case Formulation Approach. New York: Guilford Press. 


\section{Anexo 1. TEPT-Checklist}

Lea cada frase y marque la respuesta que más se ajusta a cómo se sintió usted durante la semana pasada. No piense mucho las respuestas. Lo más seguro es que si contesta de prisa, sus respuestas podrán reflejar mejor cómo se encontraba usted durante la semana pasada.

\begin{tabular}{|c|c|c|}
\hline Sentí el temblor & sí & NO \\
\hline Vi que durante o después del temblor se derrumbó algún edificio o casa & sí & NO \\
\hline Tengo un familiar o amigo al que se le derrumbó su casa & sí & NO \\
\hline Tuve un familiar o amigo atrapado en algún derrumbe & sí & NO \\
\hline Estuve atrapado en algún derrumbe & sí & NO \\
\hline Colaboré removiendo restos de algún edificio & sí & NO \\
\hline Trasladé u ofrecí primeros auxilios a víctimas del terremoto & sí & NO \\
\hline Trabajé tratando a los heridos por el terremoto & sí & NO \\
\hline Vi que alguna víctima del terremoto falleció & sí & NO \\
\hline Tengo pensamientos y recuerdos del terremoto constantemente & sí & NO \\
\hline Tengo sueños o pesadillas sobre terremotos y destrucción & sí & NO \\
\hline Siento que está sucediendo nuevamente el terremoto & sí & NO \\
\hline Se me acelera el pulso o siento palpitaciones al recordar el terremoto & sí & NO \\
\hline Tiemblo, sudo y me sudan las manos al recordar el terremoto & sí & NO \\
\hline Siento que me falta el aire al recordar el terremoto & sí & NO \\
\hline Trato de no recordar o no pensar en el terremoto & sí & NO \\
\hline Procuro no ir a lugares que te recuerden el terremoto & sí & NO \\
\hline Evito hablar del terremoto con tus amigos o familiares & sí & NO \\
\hline Se me olvidó lo que hice después del terremoto & sí & NO \\
\hline Tengo miedo de que vuelva temblar & sí & NO \\
\hline He perdido el interés en cosas que antes me gustaban & Sí & NO \\
\hline Me siento distante o alejado de mis amigos & sí & NO \\
\hline Estoy de mal humor después del sismo & sí & NO \\
\hline Me enojo muy fácilmente después del sismo & Sí & NO \\
\hline Me sobresalto ante cualquier ruido intenso. & Sí & NO \\
\hline Me cuesta mucho trabajo concentrarme para hacer alguna tarea & sí & NO \\
\hline Me cuesta mucho trabajo iniciar el sueño & sí & NO \\
\hline Durante la noche me despierto y no me puedo dormir & sí & NO \\
\hline Duermo, pero me despierto cansado & sí & NO \\
\hline
\end{tabular}




\section{Anexo 2. Registro de frecuencia e intensidad de las respuestas asociadas al TEPT}

Para identificar los síntomas, la frecuencia y la intensidad que experimenta el paciente durante la última semana se puede recurrir al siguiente formato de registro:

\begin{tabular}{|c|c|c|c|c|c|}
\hline Frecuencia & $\begin{array}{c}0 \\
\text { Ninguna }\end{array}$ & $\begin{array}{c}1 \\
\text { Una sola vez }\end{array}$ & $\begin{array}{c}2 \\
\text { Dos o tres } \\
\text { veces }\end{array}$ & $\begin{array}{c}3 \\
\text { De cuatro a seis } \\
\text { veces }\end{array}$ & $\begin{array}{c}4 \\
\text { Diariamente }\end{array}$ \\
\hline Intensidad & $\begin{array}{c}0 \\
\text { Ninguna } \\
\text { molestia }\end{array}$ & $\begin{array}{l}1 \\
\text { Ligeramente } \\
\text { molesto }\end{array}$ & $\begin{array}{c}2 \\
\text { Moderadamente } \\
\text { molesto }\end{array}$ & $\begin{array}{c}4 \\
\text { Considerablemente } \\
\text { molesto }\end{array}$ & $\begin{array}{c}4 \\
\text { Muy molesto }\end{array}$ \\
\hline
\end{tabular}

Respuesta

Frecuencia Intensidad

Imágenes, recuerdos o pensamientos dolorosos del acontecimiento

Sueños angustiosos sobre el acontecimiento

Sentir como si el acontecimiento se repitiera o lo reviviese

Experimentar ansiedad por algo que recuerda del acontecimiento

Verse físicamente inquieto por algún recuerdo del acontecimiento (aceleración de la frecuencia respiratoria, sudoración, falta de aire, náuseas)

Evitar pensamientos y sentimientos sobre el acontecimiento

Evitar hacer cosas que le recuerden el acontecimiento

Incapacidad para recordar cosas importantes relacionadas al

acontecimiento

Dificultad para disfrutar de las cosas

Sentirse alejado de los demás

Incapacidad de tener sentimientos tristes o agradables

Dificultad para imaginar cosas positivas y felices

Problemas para conciliar el sueño

Irritabilidad o estallidos de enojo

Dificultad para concentrarse

Estar siempre a la defensiva

Estar muy tenso y sobresaltarse con facilidad

Nota: Modificado de M.B. Williams y S. Poijula, 2015, Manual de tratamiento del Trastorno de Estrés Postraumático. Técnicas Sencillas y eficaces para superar los síntomas del TEPT. 


\section{Anexo 3. Instrucciones para la relajación}

Este documento nos permitirá trabajar en un procedimiento que se denomina relajación; la técnica consiste en que usted va a disminuir voluntaria y progresivamente el grado de contracción de sus músculos. Para ello, es necesario seguir las siguientes instrucciones:

Recuéstese en una cama o siéntese en una silla cómoda.

Apriete muy fuertemente su mano izquierda. Con la mano derecha toque el grado de tensión de su antebrazo.

¿Nota usted esa tensión?

Ahora, extienda su mano izquierda y coloque el brazo izquierdo sobre el abdomen. Toque con la mano derecha su antebrazo izquierdo.

¿Nota la diferencia?

Para poder iniciar la relajación es necesario que usted se encuentre calmado(a), tranquilo(a), sin que le molesten.

Piense por favor en una escena agradable. Por ejemplo, Usted está sentado(a) en una región boscosa, hay una cascada de agua cristalina, la temperatura es agradable, le permite a Ud. estar acostado(a) respirando aire puro, no hay más ruidos que los cantos de las aves...

¿Visualiza Ud. la imagen?

Ahora, respire tranquilamente. Meta aire a sus pulmones con gran profundidad. Cada vez que expulse el aire de sus pulmones intente decir relax. ¡Vamos!

Inspire profundamente, suelte el aire... Continúe respirando así, hondo, hondo...

Iniciaremos este procedimiento trabajando cambios de tensión muscular desde los pies hasta la cabeza.

¿Está usted listo(a)?

Siga respirando profundamente...

Va a contraer los dedos de los pies, como si quisiera sostener algo con los dedos de los pies... Sostenga esa posición mientras respira hondo, muy hondo.

Afloje los dedos de los pies.

Siga respirando profundamente

Ahora, estire los dedos de los pies, extienda los talones y contraiga fuertemente las 
pantorrillas... Sostenga esa posición mientras respira hondo, muy hondo.

¿Tiene la sensación de que le pesan los pies?

Afloje las piernas; siga respirando. Meta mucho aire...

Ahora arrójelo...

En este momento va a contraer los muslos, fuertemente. ¡Sostenga esa contracción!

Siga respirando profundamente.

Ahora relaje los músculos de los muslos.

Siga respirando profundamente...

Ahora contraiga fuertemente los glúteos y apriételos; siga respirando profundamente... Relaje sus glúteos...

La relajación va subiendo...

La sensación de calor va subiendo desde los pies.

Ahora contraiga los músculos del abdomen.

¡Sostenga esa contracción!

Relaje sus músculos abdominales, mientras sigue respirando profundamente...

En este momento contraerá los músculos de la espalda.

Sostenga esa posición por un momento.

Ahora, afloje los músculos de la espalda, acomódese...

A continuación, contraerá los músculos de los dos brazos, extendiéndolos fuertemente.

Sostenga esa contracción.

Afloje y siga respirando profundamente...

Ahora trabajaremos con los músculos del cuello; levante los hombros, tense los músculos del cuello, sostenga esta posición un momento.

Afloje los músculos del cuello.

Cierre fuertemente los ojos. Sosténgase, siga respirando... Relájese...

Siga respirando profundamente...

Deje que la lengua tome su lugar dentro de la boca...

En este momento, si siguió las instrucciones, se encuentra relajado.

¿Se siente descansado y calmado?

Usted puede relajarse diariamente, siguiendo estas instrucciones.

Nota: Tomado de L. Reynoso-Erazo y I. Seligson, 2001, Manual de relajación. México: UNAMCONACYT. 


\section{Anexo 4. Registro para la identificación de cogniciones asociadas al TEPT}

Si se supone que la base de la perturbación emocional y/o conductual se encuentra determinada proximalmente por los pensamientos automáticos, entonces, el conocerlos pensamientos automáticos que se presentan como parte del TEPT se vuelve una tarea fundamental. Conviene hacer una buena descripción de qué son los pensamientos automáticos y aportar ejemplos abundantes y cercanos a la experiencia del paciente. En este momento se le solicita que lleve un registro diario de estos productos para su posterior análisis. Ejemplo:

\begin{tabular}{|c|c|c|c|c|}
\hline Fecha y hora & Situación & $\begin{array}{l}\text { Pensamientos } \\
\text { automáticos }\end{array}$ & $\begin{array}{l}\text { Emociones } \\
\text { (intensidad) }\end{array}$ & $\begin{array}{l}\text { Respuesta } \\
\text { fisiológica } \\
\text { asociada }\end{array}$ \\
\hline 06/01/98 11:45 & $\begin{array}{l}\text { Viendo en las } \\
\text { noticias que } \\
\text { ocurrió un } \\
\text { temblor en } \\
\text { Indonesia }\end{array}$ & $\begin{array}{l}\text { "De seguro } \\
\text { temblará otra } \\
\text { vez en la Ciudad } \\
\text { de México" } \\
\text { "Esta vez, si } \\
\text { tiembla no podré } \\
\text { soportarlo" }\end{array}$ & Miedo $(10 / 10)$ & Taquicardia \\
\hline $\begin{array}{c}\text { Comportamientos } \\
\text { derivados }\end{array}$ & \multicolumn{2}{|c|}{$\begin{array}{l}\text { Evidencia que NO apoya } \\
\text { el pensamiento automático }\end{array}$} & \multicolumn{2}{|c|}{$\begin{array}{c}\text { Emociones posteriores a la } \\
\text { búsqueda de la evidencia que } \\
\text { NO apoya ese pensamiento } \\
\text { automático }\end{array}$} \\
\hline Llanto & $\begin{array}{r}\text { "Cuando pasc } \\
\text { mucho, sin e } \\
\text { cosas que no s } \\
\text { vida } \\
\text { "Estoy aprendi } \\
\text { diferente, lo cu }\end{array}$ & $\begin{array}{l}\text { el temblor me asust } \\
\text { nbargo, hoy ahora se } \\
\text { bía para resguardar } \\
\text { la de otros". } \\
\text { ndo a pensar de forr } \\
\text { I puede que me ayu }\end{array}$ & \multicolumn{2}{|c|}{ Miedo (3/10) } \\
\hline
\end{tabular}

Nota: Modificado de D. Greenberger y C. Padesky, 2016, El control de tu estado de ánimo. Cambia lo que sientes, cambiando cómo piensas. New York: The Guilford Press. 


\section{Acerca de los autores}

\section{Leonardo Reynoso Erazo}

Médico Cirujano, Maestro en Modificación de Conducta por la UNAM; miembro de la Society of Behavioral Medicine, la American Psychological Association, la Society for Neuroscience, la Asociación Mexicana de Psicología Social y la Sociedad Mexicana de Análisis de la conducta (SMAC); coordinador de la residencia en Medicina Conductual de la UNAM. Entre otras obras ha publicado: Cuide su corazón; Psicología y Salud, Psicología clínica de la salud: un enfoque conductual; Electrocardiografía; Sistema Cardiovascular; Diabetes tipo 2 en niños: alternativas de prevención; Hipertensión arterial: Manual de intervenciones en actividad física, alimentación y solución de problemas para niños; y Medicina Conductual: Teoría y Práctica, este último también con editorial Qartuppi.

\section{Ana Leticia Becerra Gálvez}

Licenciada en Psicología y Maestra en Psicología con residencia en Medicina Conductual por la UNAM. Docente de la Carrera de Psicología de la FES-Iztacala en el área de Psicología Clínica y de la Salud. Docente, supervisora académica y tutora de la Maestría en Psicología con Residencia en Medicina Conductual de la FES-Iztacala UNAM. Docente en cursos y diplomados en Terapia Cognitivo-Conductual y autora de artículos en revistas nacionales e internacionales. Coordinadora del libro Medicina Conductual: Teoría y Práctica, disponible en Qartuppi.com

\section{Isaías Vicente Lugo González}

Licenciado en Psicología por FES Iztacala de la UNAM. Maestro en Psicología por la UNAM, con residencia en Medicina Conductual. Diplomado en Tanatología por la escuela de profesionales en salud del Grupo Ángeles. Profesor y supervisor del Diplomado en Terapia Cognitivo Conductual, y doctorando en Psicología en la UNAM. Cuenta con diversas publicaciones en revistas indexadas y capítulos de libro. Ponente y tallerista en congresos nacionales e internacionales especializados, así como en diversas instituciones educativas y de salud. 


\section{Acerca de los revisores}

\section{Everardo Camacho Gutiérrez}

Maestro y doctor en Ciencias del Comportamiento (opción Análisis de la Conducta) por la Universidad de Guadalajara. Es profesor investigador titular en el Departamento de Psicología, Educación y Salud del Instituto Tecnológico y de Estudios Superiores de Occidente (ITESO) y miembro del Sistema Nacional de Investigadores Nivel I. Su línea de investigación es sobre el estrés y sus efectos en la salud. Entre sus publicaciones está el libro Estrés y salud: investigación básica y aplicaciones y junto con Claudia Vega-Michel coordinó el libro Autocuidado de la Salud.

\section{Benjamín Domínguez Trejo}

Doctor en Psicología. Es profesor-investigador en la Facultad de Psicología de la UNAM. Su trabajo se ha vinculado a problemas de interés nacional: tratamiento de pacientes con esquizofrenia sometidos a proceso penales (1967-1979), tratamiento y rehabilitación de poblaciones carcelarias en instituciones de custodia (1972-1986), aplicación y diseño de tratamientos psicológicos no-invasivos en problemas de salud (1987-2018), adicciones, estrés postraumático, dolor crónico, hipertensión, asma y otros. Autor de 16 libros, 49 capítulos y 100 artículos en revistas científicas nacionales e internacionales. Ha recibido 209 reconocimientos y premios.

\section{Rosa Martha Meda Lara}

Maestra en Psicología Educativa y Doctora en Ciencias de la Salud por la Universidad de Guadalajara. Es profesora-investigadora Titular "C" en el Departamento de Psicología Básica, Centro Universitario de Ciencias de la Salud, en la Universidad de Guadalajara. Miembro Fundador de ALAPSA México. Miembro del Sistema Nacional de Investigadores Nivel I. Miembro del Cuerpo académico 598 de Psicología de la Salud: Prevención y Promoción de la Salud. Fundadora del Programa Universidad Promotora de la Salud de la Universidad de Guadalajara. 
Qartuppi, S. de R.L. de C.V. está inscrita de forma definitiva en el Registro Nacional de Instituciones y Empresas Científicas y Tecnológicas (RENIECYT) con el número 1600052.

Qartuppi, S. de R.L. de C.V. es miembro activo de la Cámara Nacional de la Industria Editorial Mexicana (CANIEM) con número de registro 3751 .

Trastorno de estrés postraumático en adultos Intervención cognitivo-conductual para víctimas de sismos

ISBN 978-607-98270-7-6

DOI 10.29410/QTP.19.02

Esta obra se terminó de producir en enero de 2019.

Su edición y diseño estuvieron a cargo de:

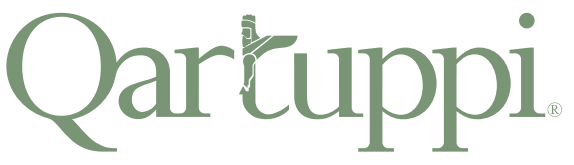

Qartuppi, S. de R.L. de C.V.

http://www.qartuppi.com 


\section{(c) $\underset{\mathrm{BY}}{(1)(3)}$}

Esta obra se publica bajo una Licencia Creative Commons Atribución-NoComercial 4.0 Internacional.

https://creativecommons.org/licenses/by-nc/4.0/deed.es 
